\title{
Análisis de la gestión curricular de los programas educativos en el Centro Penal de Atención Institucional San Rafael, Alajuela, Costa Rica
}

\author{
Management Curriculum Analysis of Educational Programs at San \\ Rafael Correctional Institution, in San Rafael, Alajuela (Centro \\ Penal de Atención Institucional San Rafael, Alajuela, Costa Rica)
}

Recibido 15 enero 2012 • Aceptado 19 junio 2012 • Corregido 24 junio 2012

Jeffrey Murillo Brenes ${ }^{1}$

afromurillo@hotmail.com

Ministerio de Educación Pública

\begin{abstract}
Resumen. El presente artículo corresponde a una investigación llevada a cabo en el Centro Penal de Atención Institucional San Rafael, Alajuela, Costa Rica. El estudio se desarrolló bajo la modalidad de investigación aplicada, desde el enfoque cualitativo de manera que profundizó en el objeto de estudio, a través de lo siguientes objetivos: Identificar las adecuaciones de los diseño curriculares que experimentan los programas educativos para su ejecución en los Centros Penales de Alajuela, Reconocer los componentes pedagógicos con que cuentan los Centros Penales para implementar los programas educativos, determinar la pertinencia de los programas curriculares según las necesidades de la población del los Centros Penales de Alajuela y identificar el sistema de evaluación de los programas curriculares utilizados por la gestión de los Centros Penales de Alajuela. Los hallazgos permitieron obtener conocimiento básico que se necesita para reestructurar no solo los programas educativos sino el procedimiento necesario para impartirlo a los discentes internos en centros penales de Costa Rica.
\end{abstract}

Palabras claves. Administración de la Educación, gestión de la educación, gestión educativa de centros penales, centros penales, educación de adultos, educación.

Abstract. This article is a research conducted at San Rafael Correctional Institution in Alajuela, Costa Rica. The study applied research based on a qualitative approach through the following objectives: identify curricular design adjustments to educational programs in this center. Besides this, to recognize pedagogical components that have correctional institutions to implement educational programs, determining the curricular pertinence to population needs, and identify the curricula assessment system used for management of this institution. The findings

1 Máster en Ciencias de la Educación con énfasis en Administración Educativa de la Universidad de Costa Rica (UCR). Bachiller en Lingüística de la Lengua española de la Universidad Nacional (UNA). Bachiller en Literatura de la Universidad Nacional (UNA) y Bachiller Actualmente se desempeña como y cursa el Posgrado en Gestión Universitaria 
allowed obtaining basic knowledge to restructure not only educational programs, but procedures required to teach learners inmates in prisons in Costa Rica.

Keywords. Educational administration, educational management, educational management of prisons, detention centers, penal institutions, prisons, adult education, education.

\section{Presentación}

La humanidad tiene la difícil tarea de promover el desarrollo cognitivo en todas sus posibilidades, a través de procesos que contribuyan con la adquisición de conocimientos útiles para enfrentar los retos tecnológicos y económicos de la actualidad, y en los cuales la educación tiene gran responsabilidad. Los procesos educativos se plantean desde distintas vertientes, tratando quizás de cubrir todas las necesidades que se desarrollan en el estrato social.

En esta coyuntura ideológica la humanidad se ha centrado en mejorar constantemente los procesos de enseñanza-aprendizaje, sometiéndolos a reestructuraciones constantes con el propósito de alcanzar los objetivos propuestos desde la visión de la educación integral que Maya (2002) propone:

La educación integral considera al hombre en sus diferentes dimensiones y potencialidades y le ofrece elementos pedagógicos orientados hacia el aprender a aprender, aprender a hacer y aprender a ser, facilitando su realización y desarrollo personal, comunitario y laboral. (p. 8)

Esa perspectiva, supondría que al parecer todas las áreas del saber, sin importar su origen, terminarán uniéndose a otras áreas y como producto de esta fusión surge nuevo conocimiento, y en consecuencia se modifica la forma en que se ejecutan generalmente ciertas tareas.

Los procesos se rectifican y reorientan constantemente, con el objetivo de actualizarlos e incluirse con todos los requisitos en el proceso de desarrollo tecnológico de la sociedad mundial en la modernidad. En ese sentido, se podría aseverar que para las naciones desarrolladas o en 
vías de desarrollo lo más importante es la formación eficiente de ciudadanos con las características necesarias para enfrentar los retos de las sociedades en constante evolución. En consecuencia, la educación es el componente principal en el que se enfocan los motivadores del desarrollo. En respuesta a ello, en la actualidad los países del primer mundo invierten sumas importantes de dinero en educación con el objetivo de transformarlas en sistemas de formación actualizada y competitiva, tal es el caso de Singapur, cuyo sistema educativo está basado en la calidad, a través de sistemas de evaluación que permiten cierto grado de excelencia.

Esas características trasforman un proyecto de educación en modelos de educación representativos de la sociedad moderna. Países como Estados Unidos presentan una propuesta de educación novedosa, motivada por acciones tecnológicas de primer orden, lo que permite a los discentes actualizar constantemente su formación y dando como producto ciudadanos efectivos para los procesos sociales y económicos, según lo expone Alva (2003):

Las nuevas tecnologías permiten incrementar considerablemente la cantidad de comunicación entre el profesor y sus alumnos independientemente del tiempo y el espacio. Con las redes telemáticas es posible que esta interacción se produzca de forma sincrónica (mediante la videoconferencia o a través del chat) o bien asincrónica (mediante el correo electrónico o el foro de discusión). Esto significa que cualquier alumno puede plantear una duda, enviar un trabajo, realizar una consulta, o hacer alguna aportación a su docente desde cualquier lugar y en cualquier momento. (p.107)

Una educación de calidad está representada por una diversidad de componentes que dinamizan los procesos de enseñanza-aprendizaje entre ellos los contenidos curriculares, que, deberían establecer relación directa con las temáticas socioculturales en boga. La expectativa debería estar orientada hacia la mejora y la actualización constantes; los países desarrollados lo saben y someten sus componentes de educación a procesos para certificarla como de calidad, a través de las normas ISO. Sobre este tema Senlle y Gutiérrez (2005) exponen: 
Como hemos afirmado, la 1a revolución educativa está en marcha y prueba de ello son las múltiples iniciativas, algunas de las cuales queremos recoger, aún pecando de injusticia, ya que en la actualidad existen muchos centros educativos, universidades y colegios que están implantando sistemas basados en la calidad total, mejora continua y normativa ISO. (p.11)

El área de la administración de la educación tiene parte en la inminente tarea de contextualizar sus esfuerzos con la situación sociopolítica y tecnológica del mundo moderno, para enriquecer el proceso y dinamizar las técnicas, para que se adapten a las necesidades que la sociedad moderna esgrime mientras se desarrolla. Ya que en definitiva todas las áreas del saber se cruzan constantemente.

El mundo moderno presenta una diversidad de posibilidades para optimizar la educación, brinda las herramientas necesarias para enfrentar los retos del nuevo mundo y pretende actualizarse en todo momento, o por lo menos esa parece ser la premisa básica de los modelos que se presentan en el nivel mundial.

La educación ha sufrido modificaciones constantes, en procura de su modernización parece que se considera como un componente esencial de la sociedad moderna, y necesita atención constante, ante todo, actualización sin embargo, estos procesos de mejora y modernización podrían estar provocando desigualdad. Pues parece que estas estructuras educativas están dirigidas a un grupo social específico, en otras palabras no son tan inclusivas y reproducen la desigualdad social, reduciendo la oportunidad a diversos grupos y obviando las verdaderas necesidades de cada contexto donde se implemente la educación. Como lo expone Aguerrondo (2001):

Otras demandas de la sociedad, que no son demandas generales, sino específicas y que surgen de las interrelaciones con otros subsistemas. El sistema cultural demanda al sistema educativo, lo que se llama en términos muy globales la reproducción de la sociedad en la cual está funcionando. (p. 6) 
Todos los grupos humanos, en cualquiera de las condiciones en que se encuentren suponen un conjunto específico de necesidades tanto físicas como intelectuales y al parecer la educación aún no contempla esta característica en toda su dimensión, por lo menos en lo que a Costa Rica se refiere.

En ese sentido, existen grupos marginados exentos de las actividades de formación educativa de avanzada, por lo tanto, se perciben estratos de desigualdad y diferencias marcadas. Esta situación parece estar relacionada con características socioeconómicas propias de ciertos contextos. Además, podría considerarse con toda atención la probable causa y también consecuencia de la desigualdad en el proceso de acceso a la educación. Por ejemplo, en Estados Unidos la desigualdad social se refleja en las estadísticas ya que la tasa de pobreza creció a $13,2 \%$ en 2008 , lo que aumenta el número de personas en pobreza a millones.

Esos datos parecen reflejar una sociedad que está estructurada en función de una minoría, pues todas las personas inmiscuidas en esa estadística tendrán posibilidades mínimas de acceder a sistemas de educación novedosos, ya que su estrato social no posee los requerimientos suficientes para adquirir las condiciones evolucionadas propuestas para la educación.

La perspectiva educativa de los centros penales parece haberse desviado de su función primordial, la administración de la educación, es la especialidad llamada a procesos para reorientar el objetivo propuesto para la pedagogía en contextos penales, pudiendo extender su función hacia la parte humanista encargada de reformar a los individuos en condición de privados de libertad, logrando un reingreso saludable a la sociedad, ya que según parece "reforma", es un sinónimo de "educación", y el ente ideológico más apto para ejecutar el proceso educativo efectivamente, es la administración de la educación.

La inserción de esta especialidad se vuelve aún más urgente en los centros penales, cuando se observa la contradictoria condición que parece hacerse latente, ya que, mientras los centros de enseñanza fortifican sus estrategias y metodologías de enseñanza, los centros penales parecen mantener el mismo objetivo con el que fueron creados desde su génesis.

Aquí se evidencia una nueva dimensión de conocimiento, debido a que, dos disciplinas están uniendo su naturaleza y creando nuevo conocimiento, es decir, se generó una nueva 
perspectiva en relación con la forma en que se aplican estrategias punibles contra la delincuencia. Es en este punto donde se pretende mostrar una relación que se ha ido forjando entre las ciencias de la educación, la administración de la educación y las cuestiones penitenciarias.

La educación y la administración de la educación adquieren nuevas y modernas condiciones, ya que, las técnicas para administrar le educación se vuelven más y más eficientes; por el otro lado, las políticas penitenciarias se estancan, sosteniendo estructuras desde los tiempos en que se crearon las cárceles.

El aislamiento social como penitencia, parece provenir desde los orígenes mismos de la humanidad, sufriendo cambios mínimos durante la historia, exceptuando la cuestión de los derechos humanos, los cuales son respetados en mayor porcentaje en la actualidad, no obstante, el objetivo primordial de las cárceles debería percibirse desde otra arista. Podría suponerse que las ciencias de la educación están irreversiblemente ingresando a nuevos contextos y transformando la idea en que ejecutan las tareas sociales, así pues se reconoce que la educación tiene como fin la formación de ciudadanos aptos para sobrellevar las obligaciones sociales y lograr, de esta manera, enfrentarse a las novedades tecnológicas y procedimentales; mientras que una cárcel debe, en conjunto, contener a personas infractoras de las leyes y preparar a los individuos para enfrentar las obligaciones sociales, a través, de las prácticas tecnológicas sanas de la sociedad, en su eventual egreso.

Desde esta perspectiva, la administración de la educación, adquiere un papel preponderante. El sistema penal debería basar su funcionamiento en políticas educativas y no en la ideología del aislamiento, la "reforma" debería ser su objetivo primario. La única forma de lograr este cambio es mediante la visión alternativa de un administrador de la educación, quien podría implementar medidas con trasfondo educativo en los procesos de reforma y crear mecanismos inclusivos de oportunidades de reintegración social efectivos. El administrador educativo permitiría eventualmente ampliar la perspectiva fijada para los centros penales, ya que, por una parte, diagnosticaría las falencias de los programas educativos implementados en los centros penales y fijaría lineamientos apegados a las necesidades reales de la actualidad, también, introduciría, paulatinamente, la visión formadora, pedagógica, humanista, y socializadora a todos los procesos implicados en el internamiento de personas en centros 
penales; visión, que parece haberse desviado o hasta suplantado por la primitiva práctica del aislamiento social.

Como puede observarse, se intenta crear una analogía entre ambas instancias, con el fin de evidenciar una continuidad temática en el sentido de que todas las áreas de la humanidad en algún momento experimentaron una simbiosis, formando una nueva perspectiva para el manejo de ciertas áreas. En ese sentido, parece que el centro penal debería ser un espacio educativo o si se quiere reeducativo; podría consignarse como un proceso de educación para la inserción a la sociedad, en consecuencia debería poseer las mismas características del sistema educativo general. Esa naturaleza podría ser implementada en los centros penales, a través de las técnicas y metodologías estructuradas por la administración de la educación, convirtiendo los centros penales en centros pedagógicos para la reinserción social. Al recibir esta clasificación surgen algunas interrogantes, dada la naturaleza de estos centros de reclusión.

No podría considerarse esa situación como una contradicción estructural del sistema educativo, Los sistemas educativos resultan excluyentes con ciertos grupos sociales. Por otra parte, podría decirse que: las cárceles únicamente deben contener al individuo infractor por un periodo de tiempo y luego regresarlo a la sociedad. Muchos de estos procesos de encierro se clasifican como procesos de "reforma", podría estar la educación obviando este conjunto humano.

Algo como esto supone una contradicción en la naturaleza educativa propuesta para la sociedad desde los modelos desarrollados del primer mundo, parece existir una división social y cultural que parece mantener procesos involutivos con modelos de desarrollo constante en una sola línea, algo así como un mundo con dos facetas temporales distintas, pero en perfecta armonía. Mientras se escudriñan nuevas técnicas de enseñanza que respondan a las necesidades sociales actuales, también se nutren las estadísticas de delincuencia, lo que en consecuencia saturan las cárceles y estas producen nuevas conductas contrarias a las vaticinadas para una sociedad educada. Como bien se afirma en el siguiente extracto del foro mundial de la delincuencia y sociedad citado por Wansley (2003):

La pérdida de confianza en el sistema puede llevar a promulgar leyes más draconianas y a dictar sentencias más severas como remedios de emergencia para mantener el 


\section{Gị: Eductión}

Revista Cientifica Digital ISSN:2215-2288

[Número publicado el 30 de J unio del 2012]

URL:http:// revista dig ital.eae.fc s.uc r.ac.cr/

orden social. Las filosofías se traducen fácilmente en una demanda popular de sentencias más largas y severa. (p.72)

Es simple, las prisiones que mantengan estructuras anticuadas y cuyos objetivos y metodologías sigan perteneciendo a los orígenes y no a la modernidad continuaran reproduciendo y repitiendo el mismo problema. ¡Un problema que insoslayablemente parece repercutir en las ciencias de la educación! Evidentemente, la administración de la educación absorbe las consecuencias de este problema, no puede obviarlas, pues se trata de un problema relacionado con la educación, con la formación, con el desarrollo social, con la igualdad de oportunidades.

Es indispensable preguntarse si las modificaciones realizadas en busca de una educación de calidad prevén estas circunstancias o simplemente se desarrollan al margen de lo expuesto, si acaso alcanzará todos los estratos de la sociedad, o por el contrario, contribuirá con la desigualdad característica de la historia.

El mundo desarrollado se encuentra con estas circunstancias extremas: necesidades que carecen de cobertura y siguen generando nuevas problemáticas mientras la solución parece apuntar únicamente a técnicas más efectivas de contención y en el peor de los casos a la fabricación de armamento más efectivo. En realidad no importa que tan bien encerrados estén, ni mucho menos la cantidad de años que pasen en esta condición, sino que lo verdaderamente importante es que estos ciudadanos pasarían en un futuro muy cercano a engrosar los procesos de las economías actuales. Su eventual retorno a la sociedad representa en las condiciones actuales un círculo vicioso, pues el encierro no representa una terapia efectiva para modificar una conducta, en consecuencia el individuo egresado de centros penales regresa a la sociedad tal vez con nuevas conductas delictivas distintas a las que ya poseía. Por lo tanto, parece ser que la educación a temprana edad es tan importante como la reeducación para individuos en contextos de apartamiento social, puesto que al final, las dos tienen el mismo objetivo: brindar las armas para insertar efectivamente a los seres humanos a la sociedad cambiante. 


\section{El problema de investigación}

En Costa Rica existe una variedad interesante de programas para implementar el currículo en distintas poblaciones: entre ellos se reconocen dentro del centro penal: Educación Abierta, Centros Integrados de Educación para Adultos. No obstante, todas estas ofertas giran alrededor del mismo universo de conocimientos.

No importa la ubicación geográfica, siempre se imparten exactamente los mismos conocimientos, con mínimas variantes, en este caso se hace referencia a la educación vocacional, que incluye en los últimos años algunas especialidades como turismo, además de la educación en zonas indígenas donde el currículo incluye historia del pueblo en cuestión.

Por otra parte, los contextos de encierro se encuentran sobrepoblados, situación que ha provocado un desbalance entre la población internada y los funcionarios encargados de su atención. Del análisis realizado por la defensoría, que se desprende del periódico El País (2010) se determinó que:

En el quinquenio estudiado, hubo un crecimiento total de 2.793 personas privadas de libertad y que es, a partir del año 2009 cuando la sobrepoblación del sistema penitenciario se eleva en forma considerable, llegando hoy en día a superar el 20\%, generando hacinamiento en algunos centros penitenciarios. (p. 1)

En consecuencia, la población no recibe la atención primordial necesaria para desenvolverse efectivamente dentro del penal y por supuesto tampoco para su eventual egreso. Parece ser que en este país también se desenvuelven dos facetas contrarias: la de las propuestas de desarrollo del sistema educativo y por el otro la del estancamiento de las cárceles.

Ante este argumento parece surgir otro detalle importante, Costa Rica necesita seguir la idea aplicada en otros países para reproducir un modelo de educación de calidad, que pueda adecuarse a las necesidades de su contexto inmediato, y que además fomente la inclusividad. No obstante, este país parece basar sus políticas en la falta de diagnóstico y planificación, 
razón de más para suponer que siempre se registrarán problemas serios de adaptación y adecuación, situación que debiera evitarse, pues como lo expone el siguiente fragmento, es necesario unir planificación a todo lo que se hace, con el fin de fomentar el desarrollo, tal y como lo expone Arias (2007):

No hay desarrollo allí donde las políticas son improvisadas, donde reina la ocurrencia o donde el miedo y la desidia llevan a repetir incansablemente las estrategias del pasado... No hay desarrollo ahí donde falta liderazgo.... No hay desarrollo allí donde falta análisis y rigor científico, ahí donde la decisión y política pública se desconectan de la evidencia empírica para valerse de la retórica como única herramienta. (p.45)

La falta de diagnóstico verdaderamente es un problema, sin este es imposible realizar planificación y por supuesto es imposible generar verdadero desarrollo, este tipo de situaciones parecen reiterarse comúnmente en contextos complejos y a los que generalmente no se fija la mirada pues parece asumirse una conducta conformista con lo que se denominan logros en materia social.

En el plano educativo, muchas instituciones cuentan con laboratorios de cómputo, y docentes especializados en ese campo, no obstante, no parece existir un acuerdo entre el resto de especialidades (materias básicas) y la computadora, pues la mayoría de planeamientos anuales no incluyen este rubro en el desarrollo de actividades, en consecuencia la informática se enseña como una materia independiente, tal cual, no existiera relación entre los demás procesos cognitivos y la informática. Esta separación de áreas cognitivas que inherentemente se unen, coinciden con una característica que parece desarrollarse en los centros penales ,ya que, se crean medios de encierro más efectivos, se piensa en cárceles de máxima seguridad y mejor y mayor cantidad de armamento. Sin embargo, ni la educación logra fusionarse con la tecnología, ni las cuestiones penales logran enlazarse con la idea de la reforma. Ambas disciplinas, reciben incentivos erróneos, no obstante, en nada suponen actualización con las necesidades sociales.

Estas contradicciones percibidas, permiten en parte comprender por qué no se logra un equilibrio que propicie un desarrollo estable, la falta de diagnóstico provoca un desconocimiento 
de las carencias reales y por lo tanto, provoca decisiones erróneas en cuanto solución de esas carencias, en realidad no se puede lograr un desarrollo real sin conocer las verdaderas necesidades.

La administración de la educación es una ciencia estructurada desde dos polos del saber que se unieron en una sola especialidad, esa genética le permite incurrir en muchas áreas del constructo social, ya que se compone de dos ramas singularmente distintas y a la vez se unen en un equilibrio necesario. En consecuencia, resulta exacta la incursión del administrador educativo, ya que en los centros penales, se desarrollan procesos de privación de libertad, encierro, aislamiento y se intenta una reforma; si el término reforma, como se intenta enlazar, es sinónimo de educación, entonces la reforma pareciera ser tarea intrínseca del administrador educativo.

La incursión de la administración de la educación en los centros penales parece ser necesaria, sin embargo, resulta complejo lograr esta evolución, ya que parece poseer anticuerpos poderosos, tal como la violencia intracarcelaria, la cual solo se combate a través de medidas de encarcelamiento más severas y armamento más sofisticado, en conjunto con la necesaria desmitificación social, concebida desde siempre, y en la que se menosprecian las oportunidades que pudiesen ofrecerse en un centro penal. Parece que una parte importante de nuestra sociedad, sostiene la idea del encierro perpetuo y la negativa al cambio de los individuos. El administrador de la educación podría variar significativamente esa filosofía, al colocar en juego todos los aspectos pedagógicos en un proceso de reforma. Para lo cual, necesita, en primer lugar cubrir todas las carencias detectadas en un diagnóstico especializado.

Ante esta situación, es muy importante develar estas carencias, pues el desarrollo sostenible implica reconocer las debilidades y transformarlas para que se adecuen al esquema social y de desarrollo vigente. Dicho pues esto, entonces se sostiene que esa parte de la sociedad en desarrollo es el ejemplo vivo a seguir, mientras la otra parte, corresponde a las prácticas anticuadas que subsisten, las cuales, por sentido común deben adecuarse para formar un solo bloque, dirigido en una sola dirección: el desarrollo.

La administración de la educación, dentro de su desarrollo, tiene la posibilidad de enfrentarse a problemáticas diversas, ha enfatizado su origen desde diversas perspectivas teóricas y reconoce en cualquier circunstancia la educación como proceso base en la 
estructuración de una sociedad desarrollada. Esta impulsa todas sus decisiones a partir del diagnóstico, proceso del que, al parecer, carecen otras instancias.

Este lapso temporal evidencia la implementación de programas educativos en centros penales, no obstante, carecen de procesos de prueba, no se realiza un diagnóstico ni se planifica un objetivo claro para esta población, simplemente se implementa un programa y de esa forma se satisface con el derecho a la educación. La administración de la educación juega un papel preponderante en la solución de un problema como el que se desarrolla en los centros penales, el problema está absolutamente ligado con el término educación y la correcta administración de este recurso, podría inminentemente transformar los procesos de reforma, convirtiéndolos en procesos resocializadores efectivos, pedagógicos y axiológicos aptos para la sociedad moderna.

La educación parece ser la clave para rectificar el objetivo destinado al sistema penal, y la administración educativa es la encargada de organizar de forma competente los procesos de enseñanza en estos contextos, asimismo los profesionales encargados de estas tareas y la metodología empleada están bajo la responsabilidad del profesional en este campo, quien probablemente podría reorientar esta institución y mejorar su desempeño.

Entonces, surge un problema que compete a la sociedad directamente, pues no podría continuar contribuyendo con un proceso improductivo en cualquier perspectiva, que además genera una serie de gastos impresionantes al estado, un componente desviado por completo de la sociedad actual y de sus objetivos, es decir, una sociedad que no intenta reparar este procedimiento, produce obstáculos en el desarrollo y malgasta capital en objetivos obsoletos. En ese sentido, resulta importante destacar que el administrador de la educación, podría reorientar todos los descritos y encaminarlos hacia el desarrollo sostenible y la inversión inteligente, dándole un valor significativo al producto final del proceso de reforma.

Las cárceles se comportan como micro sociedades con sus propias reglas, en ellas se incorporan los individuos que rompen con el esquema social, dada la naturaleza delictiva y antisocial de su comportamiento. Estos individuos están urgidos de educación que les permita asimilar los cambios a que se enfrentarán al obtener su libertad, de lo contrario el encierro no tendría un objetivo claro y se resumiría en un gasto injustificado para el estado, por lo tanto, el problema parece situarse en el contexto educativo, en la oferta educativa a que se sometan los 
privados de libertad, y a los contenidos socioculturales que se ofrecen y que permiten un desarrollo social positivo de cada interno.

Se podría optimizar el funcionamiento de los centros penales, con la incorporación de un administrador de la educación que estuviera facultado para investigar las necesidades y carencias de los contextos de encierro y disponer de los recursos más aptos para desarrollar un programa educativo a la altura de las falencias penitenciarias y la solución de sus problemas.

El problema y la posible resolución recaen directamente sobre la administración educativa quien debe organizar los componentes descritos, para que trabajen de forma efectiva y resolver una situación que perdió el horizonte y solo esta disciplina podría encauzar. Al enlazarla con lineamientos sociales y políticos de nuestro país, de forma que se logre involucrar a todas las áreas que develan el desarrollo equilibrado e inteligente.

Urge un diagnóstico de la oferta educativa ofrecida en los centros penales y por supuesto de la administración encargada de estos programas educativos. Necesita una "reforma", en los procedimientos empleados por la administración de la educación en estos centros, es necesario plantear un cambio por el bien social. Un programa de estudio integral permitirá aprovechar un margen aún más elevado del actual, las condiciones que se ofrecen en los centros penales. En ese sentido se realizó una investigación en el Centro Penal de Atención Institucional San Rafael, uno de los satélites de La Reforma ubicado en la provincia de Alajuela, Costa Rica.

En ese sentido se realizó una investigación que cubrió los siguientes objetivos:

1. Identificar las adecuaciones de los diseño curriculares que experimentan los programas educativos para su ejecución en los Centros Penales de Alajuela

2. Reconocer los componentes pedagógicos con que cuentan los Centros Penales para implementar los programas educativos.

3. Determinar la pertinencia de los programas curriculares según las necesidades de la población del los Centros Penales de Alajuela.

4. Identificar el sistema de evaluación de los programas curriculares utilizados por la gestión de los Centros Penales de Alajuela. 


\section{Referente teórico}

\section{Educación, conceptualización.}

El concepto actual de educación encierra una serie de características que en lugar de aislar al individuo como discípulo absoluto, lo incluye en un proceso contextual, grupal y de convivencia continua, Fallas y Herrera (2009) expone esta idea con mayor claridad:

La educación es un proceso, en tanto considera al individuo como sujeto de transformación cualitativa, provocando en él un tránsito de un punto a otro dentro de su maduración o desarrollo. La educación es a la vez, un proceso individual o social. Esto quiere decir que como proceso se orienta a logro de transformaciones individuales y sociales. (p. 41)

Esta definición resulta útil, debido a que desmitifica la educación como un componente de mera memorización de contenidos y desvía su objetivo hacia fines mayormente socializadores. Educación en sociedad, para el desarrollo y la evolución de cada individuo y estos como bases del desarrollo social.

Al conceptualizarse la educación, debe ampliarse la perspectiva ya que, el mundo actual posee como consigna la inclusión de cualquier individuo en el sistema educativo, en una sociedad que cambia con mucha rapidez exige procesos actualizadores constantes. Esta arista determinaría que todo humano puede integrarse, en todas las edades y en todo contexto social.

\section{Educación para adultos.}

Este concepto supone una alteración de las metodologías y los contenidos, pues su objetivo primordial supone la inserción social con posibilidades mejoradas, de modo que se fomente su desarrollo individual en sociedad. Dicha perspectiva se evidencia más claramente en las palabras de López (2009): 
La educación básica de personas adultas tiene como finalidad la de proporcionar a estas los elemento básicos de la cultura de manera que mejoren sus posibilidades de desarrollo personal y de inserción en los distintos ámbitos sociales. El itinerario formativo de estas enseñanzas no está pensado para que sea recorrido íntegramente por todas las personas, sino como un sistema flexible al que es posible incorporarse en cualquiera de sus niveles en función de la formación y la experiencia de cada persona. (p. 9)

El modelo de educación propuesto para centros penales, supone un análisis del contexto externo, aquel al cual se reintegrará inexorablemente el privado de libertad, con el fin de rescatar de este, aquellos condicionamientos que pudiesen alterar el reingreso del individuo en condiciones de encierro, y fortalecerlo en los procesos educativos, de modo que experimente un proceso de simbiosis con la experiencia personal de cada sujeto y se interiorice de forma natural.

El proceso implica una integración del conocimiento previo, sea cual sea que traiga el privado de libertad, para modificar ciertas conductas, desde la personalidad y la experiencia misma de cada discente.

\section{Administración de la educación.}

La administración de la educación se plantea como una ciencia interdisciplinaria, ya que reúne una serie de especialidades en su estructura componencial debe incluir una serie de aspectos diversos, ya que al final tiene como objetivo la organización de seres vivos en un proceso de formación sociocultural, en otras palabras es un proceso complejo y determinante para la sociedad en el que participan diversos individuos, a este respecto considera Botero (2009):

La filosofía de la educación postula la acción educativa como una relación dialéctica en la cual intervienen una serie de sujetos, directivos, profesores, estudiantes y familias de los estudiantes que toman decisiones y ejecutan acciones.... Uno de los fines de la 


\section{Q: Gestión: Educaion}

Revista Cientifica Digital ISSN:2215-2288

[Número publicado el 30 de Junio del 2012]

administración de la educación deberá encaminarse a trasformar los individuos y a la sociedad. (p. 2)

En ese sentido la administración de la educación como tal define un conjunto de acciones que involucran a todo el contexto que le rodea, ya que para encaminar el proceso necesita de todos los actores que se involucran, esto implica un conocimiento de este contexto y una relación sana con él, ya que las transformaciones deberán ser experimentadas por todos los actores, de modo que el proceso sea válido y pertinente.

Es indispensable reconocer el valor de todos los integrantes de la comunidad educativa, todos cumplen una función y la administración de la educación como ciencia reconoce todos esos valores y los utiliza como las bases para situar y encaminar el proceso educativo, la administración de la educación es una ciencia inclusiva y orientada hacia la integralidad.

El concepto de administración de la educación implica una serie de articulaciones con otras especialidades ya que, necesita acudir a diversos conocimientos para organizar los componentes de la educación, los cuales se distribuyen entre entes vivos y estrategias para mejorar la comprensión y el acercamiento con procesos de enseñanza y aprendizaje, por lo tanto su estructura permite abordar todas las características de una estructura educativa para optimizarla, a este respecto añade Hernández (2009):

La administración de la educación como disciplina académica, tiene como base técnica y operativa el proceso administrativo aplicado al proceso educativo, es decir, estudia el fenómeno educativo administrativamente, vincula la administración y la pedagogía, debido a que la administración se encarga de hacer más eficientes los distintos procesos de una organización y las educativas no son la excepción. (p. 6)

El proceso que compete a la administración de la educación está estructurado por un complejo sistema de relaciones entre docentes, discentes, padres de familia, costumbres del contexto, lenguaje, elementos inmediatos entre otros y la administración de la educación tiene 
la tarea de estudiar las relaciones que se desarrollan entre todos estos elementos, para desarrollar procesos pedagógicos eficientes y sobre todo pertinentes.

\section{Referente metodológico}

\section{Enfoque de la investigación.}

Este trabajo se realiza bajo la modalidad de investigación aplicada, desde el enfoque cualitativo de manera que se pueda profundizar en el tema y alcanzar el conocimiento básico que se necesita para reestructurar no solo los programas educativos sino el procedimiento necesario para impartirlo a los discentes internos en centros penales de Costa Rica.

El enfoque cuantitativo según Castro (1996, p.62) permite "la medición numérica a los fenómenos observados, la estadística constituye un instrumento apropiado para mediciones objetivas", este enfoque facilita la adquisición de datos inobjetables y mucho más confirmables, con el fin de evidenciar poblaciones expuestas a situaciones referentes al problema de investigación, para este fin serán útiles todos los instrumentos numéricos

El enfoque cualitativo por su parte, promueve la participación de todos los actores del entorno, lo que interesa a esta investigación, pues solo de esa manera puede resolverse un asunto de peso social, el componente mejor elegido para un contexto específico y su efectividad, tal y como lo evidencia Rueda (1999):

La apuesta por métodos cualitativos comporta estimular y afrontar la participación de todo agente social, una sensibilidad cultural, requiere prestar atención a cada proceso social, en marcado en un entorno cultural. (p. 501)

La investigación se adapta al tipo de investigación descriptiva, pretende evidenciar las condiciones de desarrollo e implementación de programas educativos en los centros penales, de manera que se trata de elaborar un marco de estudio del cual se deduce un problema con el fin de conocer carencias básicas y así, actuar posteriormente. 
Todas estas características le brindan un carácter cualitativo a la investigación, ya que, podría eventualmente convertirse en la base de una propuesta para replantear el trabajo que se realiza en los centros penales, así como los planes de atención técnica y las actividades que se estructuran para los privados de libertad.

\section{Sujetos de investigación.}

Esta investigación por su naturaleza descriptiva, permite seleccionar a los participantes bajo el criterio de conveniencia de investigador, esta porque se necesita trabajar con personal administrativo y directivo de los programas de CINDEA.

En ese sentido, se trabajó con:

- El director de CINDEA San Rafael de Alajuela (MEP)

- El coordinador nacional de servicios educativos (MJP)

- Los cinco coordinadores educativos de cada centro penal (Ministerio de Justicia)

El desarrollo de esta investigación desde la especificidad de sus categorías de análisis según sus objetivos se presenta en forma detallada en la siguiente operacionalización metodológica.

\section{Operacionalización metodológica.}

Objetivo general: Analizar la gestión curricular de los Programas Educativos desarrollados en los Centros Penales de Alajuela.

\begin{tabular}{|c|l|}
\hline Objetivo específico & $\begin{array}{l}\text { Identificar las adecuaciones de los diseños curriculares que experimentan los } \\
\text { programas educativos para su ejecución en el Centro Penal de Alajuela }\end{array}$ \\
\hline Categoría de análisis & Adecuaciones de los Diseños curriculares \\
\hline $\begin{array}{c}\text { Definición } \\
\text { conceptual }\end{array}$ & $\begin{array}{l}\text { - Las adecuaciones curriculares son “...adaptaciones y los servicios de apoyo } \\
\text { que incluyen: recursos humanos especializados, evaluaciones, metodología, } \\
\text { planta física, las cuales serán definidas por el personal del centro educativo..." } \\
\text { (La Gaceta, 2006, p.12). } \\
\text { - Implican una serie de acciones de parte del docente como: “...ajustar el } \\
\text { programa (contenidos, metodología, evaluación) y poder ofrecer experiencias } \\
\text { apropiadas a las necesidades de los estudiantes... Y que incluyen }\end{array}$ \\
\hline
\end{tabular}




\begin{tabular}{|c|l|}
\hline & modificaciones en los recursos, el contenido y las técnicas de enseñanza" \\
Vargas (2001, p.8). & $\begin{array}{l}\text { - Las adecuaciones curriculares son: "una determinada concepción educativa } \\
\text { en términos de lo individual, lo social y lo cultural. Así mediante la planificación } \\
\text { y ejecución del currículo se fortalece el logro del tipo de hombre y de sociedad } \\
\text { que el grupo demanda del sistema educativo Fallas y Herrera (2009, p.43). } \\
\text { - Dentro de las adecuaciones curriculares se debe tomar en cuenta una serie } \\
\text { de dimensiones que son parte del currículum, tales como "...la social, } \\
\text { económica, cultural e histórica del currículum, las cuales no se pueden } \\
\text { visualizar aisladamente, por ser un todo integral, que vienen a ofrecer como } \\
\text { resultado final, el tipo de hombre que está formando la sociedad" Garbanzo } \\
\text { (2001, p.26). }\end{array}$ \\
\hline Definición & $\begin{array}{l}\text { Conjunto de modificaciones realizadas a los conocimientos específicos, las } \\
\text { técnicas de enseñanza, el currículo, las adaptaciones sociales y tecnológicas y } \\
\text { la contextualización con los requerimientos de la sociedad, al plan de estudios } \\
\text { ofrecido en el Centro Penal de San Rafael de Alajuela. }\end{array}$ \\
\hline Indicadores & $\begin{array}{l}\text { - Adaptaciones curriculares llevadas a cabo por los docentes en: programas, } \\
\text { contenidos, evaluación y lo tecnológico. } \\
\text { - Metodologías educativas, que incluye técnicas de enseñanza, adaptadas a } \\
\text { las necesidades de los centros penales. } \\
\text { - Ajustes de la infraestructura requerida para implementar el plan de estudios } \\
\text { en el centro penal. } \\
\text { - Concepción implícita en los ajustes curriculares sobre la persona que se } \\
\text { desea formar. } \\
\text { - Las modificaciones curriculares para implementar el programa educativo, } \\
\text { toma en cuenta el contexto social, económico, cultural e histórico de la } \\
\text { población beneficiaria. }\end{array}$ \\
\hline Instrumentalización \\
$\begin{array}{l}\text { Mediante cuestionario dirigido a docentes } \\
\text { Mediante entrevista dirigida a funcionarios administrativos del CiNDEA } \\
\text { Mediante entrevista dirigida a administrativos promotores de la implementación } \\
\text { del programa en centros penales. }\end{array}$ \\
\hline
\end{tabular}

\begin{tabular}{|c|c|}
\hline Objetivo específico & $\begin{array}{l}\text { Reconocer los componentes pedagógicos con que cuentan los Centros } \\
\text { Penales para implementar los programas educativos. }\end{array}$ \\
\hline Categoría de análisis & Componentes pedagógicos \\
\hline $\begin{array}{l}\text { Definición } \\
\text { conceptual }\end{array}$ & $\begin{array}{l}\text { - La pedagogía se define desde la perspectiva de Orozco (2008, p.5) como una } \\
\text { "praxis social de recontextualización de saberes en la cual los procesos de } \\
\text { intermediación cultural constituyen la práctica del maestro, las necesidades } \\
\text { socioculturales en su conjunto son las que determinan la orientación de esta } \\
\text { práctica y el reconocimiento de la cotidianidad como referente para la } \\
\text { aproximación a los problemas del mundo" } \\
\text { - Por su lado Peralta (2008, p. } 41-45) \text { considera a la pedagogía como un } \\
\text { "conjunto de elementos que regulan y organizan el proceso de enseñanza y } \\
\text { aprendizaje: la auto-actividad o autoconstrucción del conocimiento, toda } \\
\text { actividad educativa debe sustentarse en el bienestar integral, toda situación de }\end{array}$ \\
\hline
\end{tabular}




\begin{tabular}{|c|c|}
\hline & $\begin{array}{l}\text { aprendizaje debe ser oportuna y pertinente, toda situación de aprendizaje } \\
\text { deber ser eminentemente adecuada a la singularidad, toda situación de } \\
\text { aprendizaje debe considerar los significados propios, toda situación de } \\
\text { aprendizaje debe buscar situaciones lo más naturales y contextualizadas } \\
\text { posibles" } \\
\text { - Para Orozco (2008) y Peralta (2008) un componente pedagógico se define } \\
\text { como un conjunto de elementos que regulan y organizan el proceso de } \\
\text { enseñanza- aprendizaje, son regulados por las necesidades socioculturales del } \\
\text { contexto y se utilizan como referentes de acercamiento a la resolución de los } \\
\text { problemas de su mundo. Estos componentes deben ser pertinentes, } \\
\text { adecuados a la singularidad, y contextualizados al máximo. }\end{array}$ \\
\hline $\begin{array}{l}\text { Definición } \\
\text { Operacional }\end{array}$ & $\begin{array}{l}\text { Son un conjunto de saberes culturales, sociales, geográficos, históricos, } \\
\text { científicos, y más, que deben ser impartidos mediante técnicas definidas por las } \\
\text { necesidades socioculturales. Estos componentes son una serie de elementos } \\
\text { aplicables a la enseñanza, entre ellos: autoconstrucción del conocimiento, } \\
\text { bienestar integral, actividades pertinentes, considera el conocimiento previo y } \\
\text { contextualiza el método y los conocimientos impartidos }\end{array}$ \\
\hline Indicadores & $\begin{array}{l}\text { - Los conocimientos impartidos y las técnicas de enseñanza se definen por el } \\
\text { contexto y las necesidades socio-culturales. } \\
\text { - El docente estructura su función docente en principios como: } \\
\text {-Autoconstrucción } \\
\text {-Bienestar integral } \\
\text {-Conocimientos pertinentes al contexto } \\
\text {-Desarrolla su clase a partir del conocimiento previo } \\
\text {-Utiliza el contexto inmediato como referente para el método de enseñanza. } \\
\text {-El administrador de la educación supervisa el cumplimiento de la inserción de } \\
\text { componentes en el trabajo diario de la clase, y propone talleres de inducción y } \\
\text { actualización para los docentes referidos a temáticas de pedagogía } \\
\text { contextualizada para los centros penales. } \\
\text {-Currículo pertinente. } \\
\text {-Contextualización del método y los conocimientos impartidos. } \\
\text {-El discente se identifica con el proceso de enseñanza- aprendizaje. } \\
\text {-Reconoce elementos de su contexto en las dinámicas de clase, considera } \\
\text { pertinente el conocimiento adquirido para su situación actual y futura. }\end{array}$ \\
\hline Instrumentalización & $\begin{array}{l}\text { Mediante cuestionario dirigido al personal docente } \\
\text { Mediante entrevista a administradores y coordinadores } \\
\text { Mediante actividad de pregunta abierta a estudiantes }\end{array}$ \\
\hline
\end{tabular}

\begin{tabular}{|c|l|}
\hline Objetivo específico & $\begin{array}{l}\text { Identificar los procesos de evaluación de los programas curriculares utilizado } \\
\text { por la gestión del centro penal San Rafael de Alajuela }\end{array}$ \\
\hline Categoría de análisis & Procesos de Evaluación de programas curriculares \\
\hline $\begin{array}{c}\text { Definición } \\
\text { conceptual }\end{array}$ & $\begin{array}{c}\text { - La evaluación constituye una "actividad vital para auscultar si la educación } \\
\text { genera realmente un alto valor agregado en la formación de los educandos, } \\
\text { idóneo para promover a niveles destacables el desarrollo integral de un país. }\end{array}$ \\
\hline
\end{tabular}




\begin{tabular}{|c|c|}
\hline & $\begin{array}{l}\text { La evaluación de una necesidad proporciona datos para identificar y } \\
\text { subsecuentemente eliminar necesidades primordiales de nuestro campo de } \\
\text { interés. Las carencias, cuando se documentan, proporcionan información } \\
\text { básica para el establecimiento de metas valederas, con el fin de asegurarnos } \\
\text { todavía más de que nuestro producto educativo es pertinente. Lafourcade, } \\
\text { (2009, p.123) } \\
\text { - Programa curricular según (Hernández, 2006) es una estructura donde se } \\
\text { introducen los contenidos teóricos, estos se descomponen en fundamentos } \\
\text { teóricos, problemáticas disciplinares y posibles aplicaciones } \\
\text { - La evaluación de programas educativos consiste en auscultar si los } \\
\text { contenidos teóricos, los fundamentos teóricos, las problemáticas disciplinares } \\
\text { y sus posibles aplicaciones, generan realmente un valor agregado en la } \\
\text { formación de los educandos de modo que puedan eliminarse las carencias } \\
\text { del contexto educativo, así se establecen metas valederas para que el } \\
\text { proceso resulte pertinente. (Lafourcade, } 2009 \text { y Hernández 2006) }\end{array}$ \\
\hline $\begin{array}{l}\text { Definición } \\
\text { Operacional }\end{array}$ & $\begin{array}{l}\text { El proceso de evaluación de programas curriculares se constituye como un } \\
\text { proceso revisión que permite eliminar carencias y establecer metas pertinentes } \\
\text { a las acciones del programa curricular con base en los objetivos planteados } \\
\text { para la educación en el CAI San Rafael. }\end{array}$ \\
\hline Indicadores & $\begin{array}{l}\text { - Revisión de los resultados obtenidos semestralmente } \\
\text { - Chequeo del nivel de deserción y la razón del aumento o disminución. } \\
\text { - Revisión constante sobre el cumplimiento de objetivos del programa } \\
\text { curricular de parte de la dirección. } \\
\text { - El docente incluye nuevos contenidos teóricos pertinentes en ciertos periodos } \\
\text { para ajustarse a los objetivos del programa curricular. }\end{array}$ \\
\hline Instrumentalización & $\begin{array}{l}\text { - Mediante entrevista a administradores } \\
\text { - Mediante cuestionario a docentes }\end{array}$ \\
\hline Objetivo específico & $\begin{array}{l}\text { Determinar la pertinencia de los programas curriculares según las necesidades } \\
\text { de la población del los Centros Penales de Alajuela. }\end{array}$ \\
\hline Categoría de análisis & Pertinencia de Programas Curriculares \\
\hline $\begin{array}{l}\text { Definición } \\
\text { conceptual }\end{array}$ & $\begin{array}{l}\text { - La pertinencia se define como la facultad de poner en contacto los } \\
\text { componentes que articulan la sociedad, para que se desarrollen en forma } \\
\text { sincronizada, según Méndez (2002, p. 18) "ser pertinente es estar en contacto } \\
\text { con: -las políticas, el mundo de trabajo, -con la cultura y las culturas, -siempre y } \\
\text { en todas partes, con los docentes y los estudiantes". } \\
\text { - Un programa curricular se define como "un plan sistemático diseñado por un } \\
\text { educador como medio al servicio de las metas educativas, tanto a los efectos } \\
\text { de su elaboración como de su posterior evaluación". Pérez (2000.p, 268) } \\
\text { - El programa educativo debe estar estructurado de "unas metas u objetivos } \\
\text { que obviamente han de ser educativos, deben estar acomodadas las } \\
\text { características de los destinatarios en su contexto de referencia...". Pérez } \\
(2000, \text { p.269) }\end{array}$ \\
\hline
\end{tabular}




\begin{tabular}{|c|c|}
\hline & $\begin{array}{l}\text { - La pertinencia de programas educativos se define como la facultad de } \\
\text { contactar las metas y objetivos educativos con el mundo del trabajo, la cultura } \\
\text { y adecuado a las características de los destinatarios del contexto de referencia, } \\
\text { diseñado al servicio de su elaboración y posterior evaluación. (Méndez, } 2002 \text { y } \\
\text { Pérez, 2000) }\end{array}$ \\
\hline $\begin{array}{l}\text { Definición } \\
\text { Operacional }\end{array}$ & $\begin{array}{l}\text { La articulación armoniosa entre el programa educativo que se ofrece en el } \\
\text { centro penal San Rafael y la atención integral de las necesidades educativas } \\
\text { de la población privada de libertad del CAI San Rafael. } \\
\text { Los programas curriculares son planes sistemáticos diseñados por funcionarios } \\
\text { especialistas en educación donde se expresan los objetivos, contenidos y } \\
\text { metas de la educación, siempre con la perspectiva de atender integralmente las } \\
\text { necesidades educativas reales del contexto penal donde se implementa. }\end{array}$ \\
\hline Indicadores & $\begin{array}{l}\text { - El administrador de la educación escoge un programa - educativo dadas sus } \\
\text { características:-metas y -contenidos en contacto con las políticas, sociales y } \\
\text { culturales de la sociedad. } \\
\text { - Los docentes ajustan su plan de trabajo, de acuerdo con:-metas,-objetivos,- } \\
\text { relación de metas y objetivos con las características del contexto } \\
\text { - Los objetivos y contenidos están en contacto con las políticas, el mundo del } \\
\text { trabajo, el entorno socio-cultural } \\
\text { - Los estudiantes reconocen políticas, características del mundo del trabajo y } \\
\text { especificidades del entorno socio cultural en las dinámicas de clase y los } \\
\text { procesos educativos }\end{array}$ \\
\hline Instrumentalización & $\begin{array}{l}\text { - Mediante entrevista a administradores } \\
\text { - Mediante cuestionario a docentes }\end{array}$ \\
\hline
\end{tabular}

\section{Instrumentalización.}

Los instrumentos aplicados para obtener la información, se dividieron en dos formatos distintos, dirigidos a personas que por su función dentro del contexto que se investiga, pudieron aportar información pertinente a los objetivos planteados al inicio de este estudio.

El primer instrumento es una entrevista dirigida al director del programa en cuestión y a los cinco coordinadores de los departamentos educativos de los centros penales, está estructurada por 10 preguntas, cuyas respuestas permiten visualizar las reacciones físicas y las opiniones personales, en consecuencia resulta muy útil, ya que el acercamiento permitió visualizar las reacciones directas de los implicados así como el conocimiento relacionado con el objeto de estudio de esta investigación. 
El segundo instrumento es un cuestionario dirigido a los docentes, ellos son testigos directos del proceso en estudio, y son los responsables de ponerlo en funcionamiento, su reacción individual ante las preguntas permite visualizar hasta donde llega su conocimiento acerca del programa curricular en el que desarrollan su trabajo y el contexto donde se desarrolla dicho programa.

\section{Análisis de la información}

El análisis se realizó desde la administración de la educación, la cual como ciencia, separó el programa en varios componentes elementales para su eventual análisis y comprensión. Los componentes que se escogieron para el análisis se presentan a continuación:

- Adecuación de los diseños curriculares

- Componentes pedagógicos

- Pertinencia de los programas curriculares

- Procesos de evaluación de programas curriculares

El análisis de los componentes se realizó con grupos distintos, quienes por su ubicación y funciones, están directamente ligados al proceso que se analiza: director de CINDEA, coordinadores y personal docente. El análisis de los resultados obtenidos se presenta según las categorías de análisis definidas para la investigación.

\section{Adecuaciones de los diseños curriculares.}

La primera de las categorías, de acuerdo con las políticas institucionales establecidas por la Ley 7600, en La Gaceta (2006, p.12), son aquellas "las adaptaciones y los servicios de apoyo que incluyen: recursos humanos especializados, evaluaciones, metodología, planta física, las cuales serán definidas por el personal del centro educativo...". Por lo tanto, se debían identificar todas las adaptaciones realizadas en todas las áreas posibles: infraestructura, metodologías y contenidos, entre otros, que fueron realizadas en un inicio cuando se decidió 
implementar este programa en centros penales, asimismo como las acciones ejecutadas por el personal docente en su espacio pedagógico, o como lo define Vargas (2001), quien lo identifica una adecuación curricular como un proceso educativo adecuado a la realidad del discente:

Las adecuaciones curriculares implican una serie de acciones de parte del docente como el .ajustar el programa contenidos, metodología, evaluación y poder ofrecer experiencias apropiadas a las necesidades de los estudiantes... Y que incluyen modificaciones en los recursos, el contenido y las técnicas de enseñanza. (p. 8)

El análisis de este elemento involucra entonces tres áreas, el papel del gestor como administrador y supervisor del desarrollo del programa, el papel docente como desarrollador del programa y el estudiante como cliente directo de este proceso.

Desde la administración de la educación, estos tres componentes funcionan como entes independientes en su objetivo, pero como estructura tripartita en la ejecución adecuada del programa curricular. Es importante destacar, que la adecuación se vislumbra como las adaptaciones que se realizan en los elementos que estructuran el programa, a partir del diagnóstico realizado en el contexto, con el fin de adecuar todos los procesos cognitivos y acceder con eficiencia a la población que lo recibirá.

Las adecuaciones, realizadas en la implementación del programa educativo CINDEA para ejecutarlo en centros penales, es un tema que se analizó con docentes y administrativos directamente e indirectamente con estudiantes, de la respectiva investigación, se obtuvieron datos muy importantes, estos se presentan de forma esquematizada en la siguiente figura: 
Figura 1

Adecuaciones Curriculares

Docentes refieren:

No realizar cambio significativo. realizar cambios en el tamaño de la letra Modificar contenidos, e incluir artículos electrónicos en clase, como medida de actualización Adecuar metodología por individuo Aplicar indicadores referidos.
El director no reporta modificación alguna, y refiere ordenamiento administrativo. Las coordinadoras reportan ajustes a la infraestructura existente, pero no se apega al indicativo de la categoría

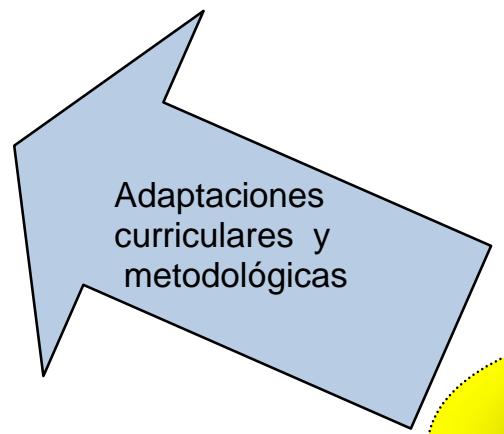

Adecuación de los diseños curriculares

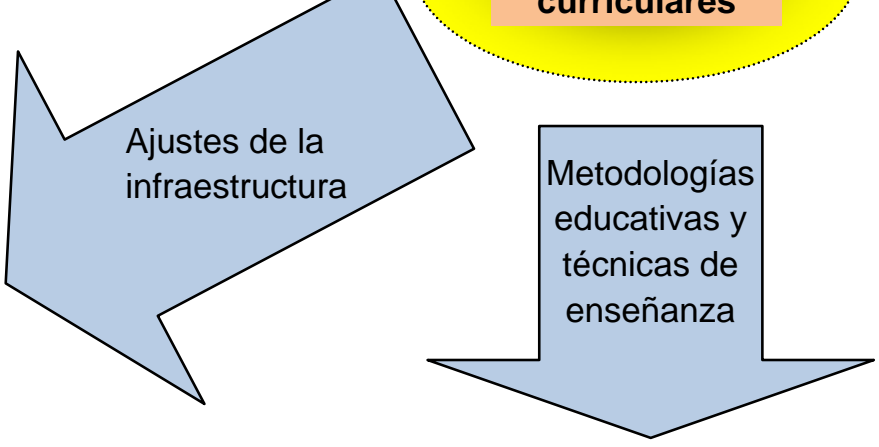

Docentes refieren metodología sin cambio Diagnóstico inicial de necesidades Enfoque constructivista No mencionan orientación, ni cambios realizados No reconocer necesidad de cambio

Fuente: Elaboración propia, 2011.

\section{Adaptaciones curriculares y metodológicas.}

El análisis permite observar una particularidad del proceso, la mayor parte de los docentes realiza algún tipo de adecuación, no obstante, están basadas en principios personales, no institucionales, es decir, cada adecuación se realiza por decisiones personales, no existe un consenso para adaptar los componentes, lo cual se opone a lo referido por La 
Gaceta (2006, p.12) en relación con las "adaptaciones a los servicios de apoyo que incluyen: recursos humanos especializados, evaluaciones, metodología, planta física, las cuales serán definidas por el personal del centro educativo". Las adecuaciones metodológicas referidas por el personal docente se vislumbran más como resultado de decisiones de impulsivas ante situaciones inesperadas, no como resultado del análisis de un equipo.

Es importante destacar que las adaptaciones deberían responder a las características del contexto, de la población, con el objetivo de brindarle a esa población una metodología más adecuada a las características sociales, culturales y de interrelación personal, tal y como lo define Vargas (2001):

Una serie de acciones de parte del docente como: "ajustar el programa (contenidos, metodología, evaluación y que incluyen modificaciones en los recursos, el contenido y las técnicas de enseñanza. (p.8)

En los casos evidenciados, solo un dato recopilado corresponde con esa con la explicación, ya que inserta técnicas distintivas como la calculadora, el resto están más relacionados con reacciones inmediatas a situaciones oportunas, que al reconocimiento de necesidades de los discentes, ya que no se presentan como modificaciones ni de recursos, ni de contenidos, esa población recibe el mismo currículo que se recibe en cualquier contexto formal de educación.

\section{Metodologías educativas y técnicas de enseñanza.}

Las adaptaciones metodológicas deben incluir un cambio en las dinámicas de clase, de forma que el discente se comprometa con el proceso al reconocer aspectos lúdicos o atractivos para lograr la interiorización de los contenidos. Desde la administración de la educación, es necesario implementar este tipo de modificaciones, ya que un, proceso educativo debe resultar en una oferta a la cual se acceda por gusto y no como una obligación. En consecuencia, el administrador debe procura que el docente realice adaptaciones para que su lección sea un espacio liberador, y ofrecer al discente el contexto más adecuado de aprendizaje, según la 
población que se atiende, tal y como lo define Vargas (2001, p.8) "poder ofrecer experiencias apropiadas a las necesidades de los estudiantes y que incluyen modificaciones en las técnicas de enseñanza".

Los datos recopilados evidencian una tendencia a realizar adaptaciones a ciertos elementos de la actividad mediadora, como el tamaño de la letra, además se menciona el constructivismo como orientación ideológica para socializar el conocimiento, por otra parte, también, se dan casos donde no se aplican adecuaciones de ningún tipo. Es indispensable, mencionar que este tipo de adaptación no se apega a la concepción, que implica el contexto como mediador para escoger y operacionalizar las técnicas y metodologías más adecuadas al contexto, en ese sentido Fallas y Herrera (2009, p.43) asegura que "las adecuaciones curriculares son una determinada concepción educativa en términos de lo individual, lo social y lo cultural" y cada una de lasas adaptaciones referidas, responden al conocimiento adquirido, 0 las situaciones imprevistas que surgen durante el proceso de enseñanza y aprendizaje.

\section{Ajuste de la infraestructura.}

Las adecuaciones se estipulan en todas las áreas de un proceso educativo, desde el planeamiento docente, los contenidos, hasta la creación de espacios físicos aptos para los discentes que se atienden. En ese sentido la administración de la educación cumple un papel muy importante, ya que necesita analizar detenidamente varios aspectos entre los que destacan la población, el nivel económico, el aspecto cultural, y las relaciones interpersonales, entre otros para modificar o crear la infraestructura más adecuada. En ese caso Vargas (2001, p. 8) asegura que las adecuaciones implican "modificaciones en los recursos" al igual que la Ley 7600 , la cual estipula adaptaciones a la planta física, según las necesidades de la población que se atiende.

Los datos recopilados evidenciaron la existencia de procesos de mejora, creación o modificación de la infraestructura existente, no obstante, esas mejoras respondieron a aspectos como crecimiento demográfico en el contexto inmediato, o a situaciones propias de crecimiento del centro penal, por lo tanto, ningún dato de los recopilados coincide con el indicador. 


\section{GGestion:}

[Número publicado el 30 de Junio del 2012]
Revista Cientifica Digital ISSN:2215-2288

URL:http:// revista dig ital.ea e.fc s.uc r.ac.cr/

\section{Contraste de datos y los indicadores con la categoría.}

Los datos recopilados permitieron observar niveles muy bajos de apego por las categorías de análisis, en el sentido de que no se realizaron adaptaciones a los diferentes componentes del programa educativo para su implementación en centros penales,

No se ajustó el programa a las características del contexto, ya que es evidente que no se conocen esas características, solamente ese aspecto provoca una serie de deficiencias en la implementación del programa, este desconocimiento impide que se contextualicen los contenidos y metodologías, así como limita el escogimiento de técnicas de enseñanza adecuadas y modificaciones en la infraestructura, que permitan el desarrollo efectivo del programa educativo.

Con el fin de evidenciar el nivel de adecuación curricular implementado en los programas educativos, desarrollados en centros penales se ofrece un diagrama que evidencia el nivel de cada indicador, según el análisis de resultados.

Los procesos de adecuación del programa educativo para implementarlo en centros penales, se visualizan más claramente en la siguiente imagen:

Figura 2

Nivel de adecuación curricular según sus componentes al programa CINDEA en centros penales

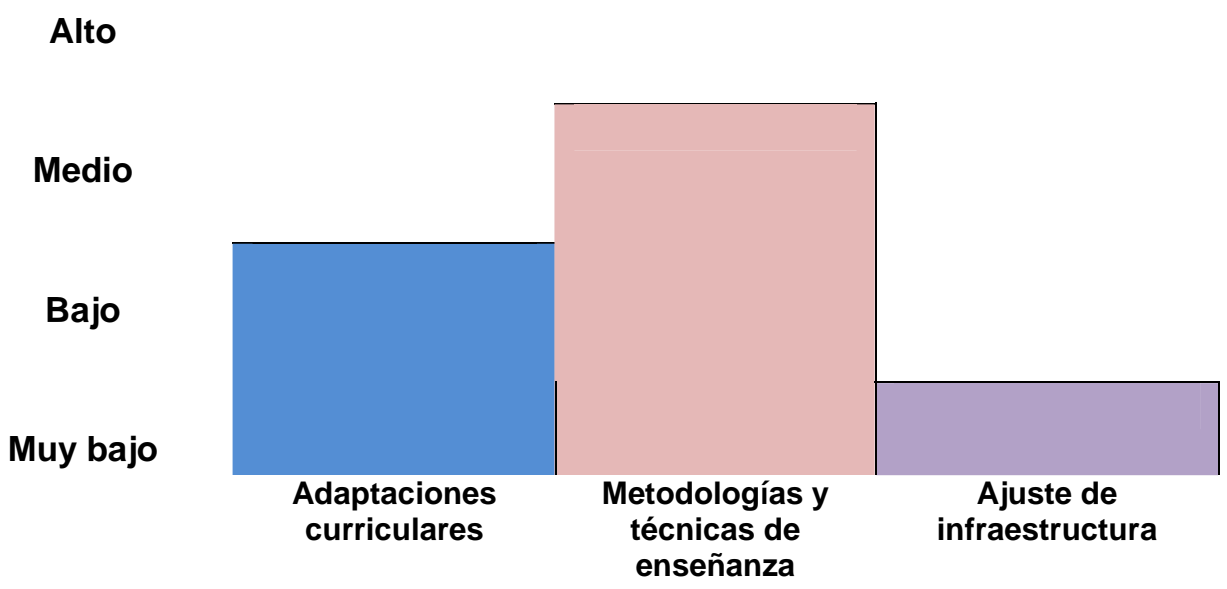

Fuente: Elaboración propia, 2011. 


\section{Componentes pedagógicos}

Un programa educativo puede considerarse como una herramienta que permite procesar un currículo de conocimientos a una población específica, sin embargo debe considerar las características de esa población para adecuar ese proceso a las características y necesidades de la población. El programa como tal se compone de elementos que al enlazarse permiten desarrollar el proceso de enseñanza - aprendizaje. Los elementos corresponden por una lado a conjuntos de conocimientos sociales y culturales así como elementos aplicables a la enseñanza, en ese sentido, Peralta (2008, p. 41-45) considera a la pedagogía como un "conjunto de elementos que regulan y organizan el proceso de enseñanza y aprendizaje: la auto-actividad o autoconstrucción del conocimiento".

Un componente pedagógico se define como las herramientas indispensables para lograr transformar el proceso de enseñanza y aprendizaje, en un entorno natural, donde el conocimiento se genere a través de actividades orientadas adecuadas. Orozco (2008) refiere que un componente pedagógico se define como:

Procesos de intermediación cultural que constituyen la práctica del maestro, las necesidades socioculturales en su conjunto son las que determinan la orientación de esta práctica y el reconocimiento de la cotidianidad como referente para la aproximación a los problemas del mundo. (p. 5)

En la práctica docente, el administrador de la educación está en la tarea de aportar elementos, conocimientos y capacitaciones, para que facilitador logre intervenciones con los discentes, cuyo objetivo sea impartir conocimientos a través de los elementos actualizados, para que ese conocimiento impartido resulte oportuno y adecuado a la población.

La figura siguiente representa los datos recopilados más relevantes de la categoría en estudio. 
Figura 3

\section{Componentes pedagógicos}

Componentes

pedagógicos

\begin{abstract}
-El director refiere desconocer este proceso; las coordinadoras tienen un consenso en que se implementó como respuesta a un derecho institucional. -Coordinadora refiere el proceso como medio para alcanzar beneficios.

-Ninguna aplica al indicador. -Docentes no refieren inclusión de características. -Docentes refieren cambios, no mencionan ninguno. Ninauna anlica al indicador.
\end{abstract}

\section{Capacitaciones} constantes

-Docentes refieren recibir una inducción básica sobre le programa y el contexto. -Docentes refieren no recibir capacitación nunca. -El director refiere una capacitación ética-estética y ciudadanía y otra en evaluación. - Las coordinadoras no refieren capacitación dirigida a nadie.

A continuación se presenta el análisis de los datos desde la perspectiva de cada indicador.

\section{Inclusión de características del contexto.}

Las adecuaciones curriculares implican un conocimiento teórico y de aplicación, para llevarlas a cabo en forma efectiva. El administrador de la educación, es responsable de crear los perfiles necesarios para mostrar al docente un acercamiento inicial del contexto donde se pretende ejecute su tarea pedagógica en forma efectiva. Ese proceso asegura que el plan de trabajo docente, en todas sus etapas, sea adecuado al aprendizaje del discente. Esto indica 
que la proyección del proceso educativo debe incluir en su estructura varias dimensiones del contexto inmediato, en ese sentido, refiere Garbanzo (2001):

las adecuaciones curriculares deben tomar en cuenta una serie de dimensiones que son parte del currículum, tales como la social, económica, cultural e histórica del currículo, las cuales no se pueden visualizar aisladamente, por ser un todo integral, que vienen a ofrecer como resultado final, el tipo de hombre que está formando la sociedad. (p. 26)

Un docente que pretenda realizar adaptaciones a sus metodologías o implementar nuevas técnicas, debe reconocer los componentes del contexto donde se desarrolla. La administración de la educación, como ciencia, está en la responsabilidad de analizar los espacios donde se implementan programas de educación, con el objetivo de introducir en su estructura, las características del contexto, y transformar en un proceso más natural el aprendizaje.

Los datos recopilados en este indicador permitieron observar un desapego total por todo lo que define una adecuación curricular como tal, desde el desconocimiento por parre del área administrativa, lo que explica porque el programa parece no cumplir con las características necesarias para asegurar éxito del proceso de enseñanza y aprendizaje, en conjunto con las reacciones del personal docente, de los cuales solo uno reconoció características internas del contexto y admitió incluirlas en su proceso docente.

Los datos permitieron observar que no existe un nexo con lo esperado por la ciencia como tal, en lo referente a las adecuaciones, ya que no se acerca a ninguna de las características teóricas descritas, entre las que destacan Garbanzo (2001) con su referente de las dimensiones del currículo, ni con Herrera (2009) y su percepción del individuo, la sociedad y la cultura. Los datos recopilados hacen más referencia a adecuaciones ante lo imprevisto, que a un estudio de la población que se atiende.

\section{Capacitaciones constantes.}

Un programa educativo debe evolucionar en forma paralela que su entorno, ya que, el factor humano y todo aquello que le compete cambia constantemente con él. Por lo tanto, el 
factor educativo, no podría detenerse, ni mucho menos suponer que su estructura es la más apta en todos los tiempos. La administración de la educación como ciencia implica continua actualización de todos los elementos que le estructuran, y los procesos educativos son parte esencial de esta ciencia.

Por lo tanto, la necesidad de capacitación, es un componente pedagógico indispensable para el desarrollo efectivo de un programa educativo, y para lograr esa característica es necesario realizar capacitaciones y actualizaciones constantes con el personal inmerso en el programa educativo. En esa línea de pensamiento un administrador de la educación debe comprender y convertir en una forma de vida, el postulado de Peralta (2008) y Orozco (2008), quienes refieren a un conjunto de elementos pertinentes, apropiados y contextualizados que regulan y organizan el proceso de enseñanza- aprendizaje.

Para organizar un proceso de educación, en este caso un programa educativo, necesita estar contextualizado al máximo, y en ese sentido se muestra como una necesidad la capacitación y contextualización constante.

Los datos recopilados evidenciaron que no existen procesos de capacitación para los docentes, quienes asumen la tarea de conocer el contexto, basados en la experiencia que se adquiere, durante el proceso, no existe un compromiso serio con esa tarea, y rompe la relación intrínseca entre la práctica docente y los postulados teóricos que defienden Peralta (2008) y Orozco (2008), cuando postulan la necesidad de contextualizar al máximo el programa educativo.

\section{Análisis global del grado de cumplimiento de los indicadores en la implementación del programa educativo en centros penales.}

La administración de la educación en su enfoque científico, asume la tarea de actualizar y contextualizar los procesos que supervisa, tras el análisis de los datos de esta categoría, se descubre que el programa educativo carece de este rubro de la administración de la educación, lo que coloca en una posición muy comprometedora este programa, ya que, por el tipo de población que atiende, necesita actualización constante o 
perdería por completo el sentido y no tendría función alguna el gasto económico que significa desarrollarlo.

La siguiente figura indica el grado de cumplimiento de los indicadores de esta categoría.

Figura 4

Procesos de evaluación de programas curriculares

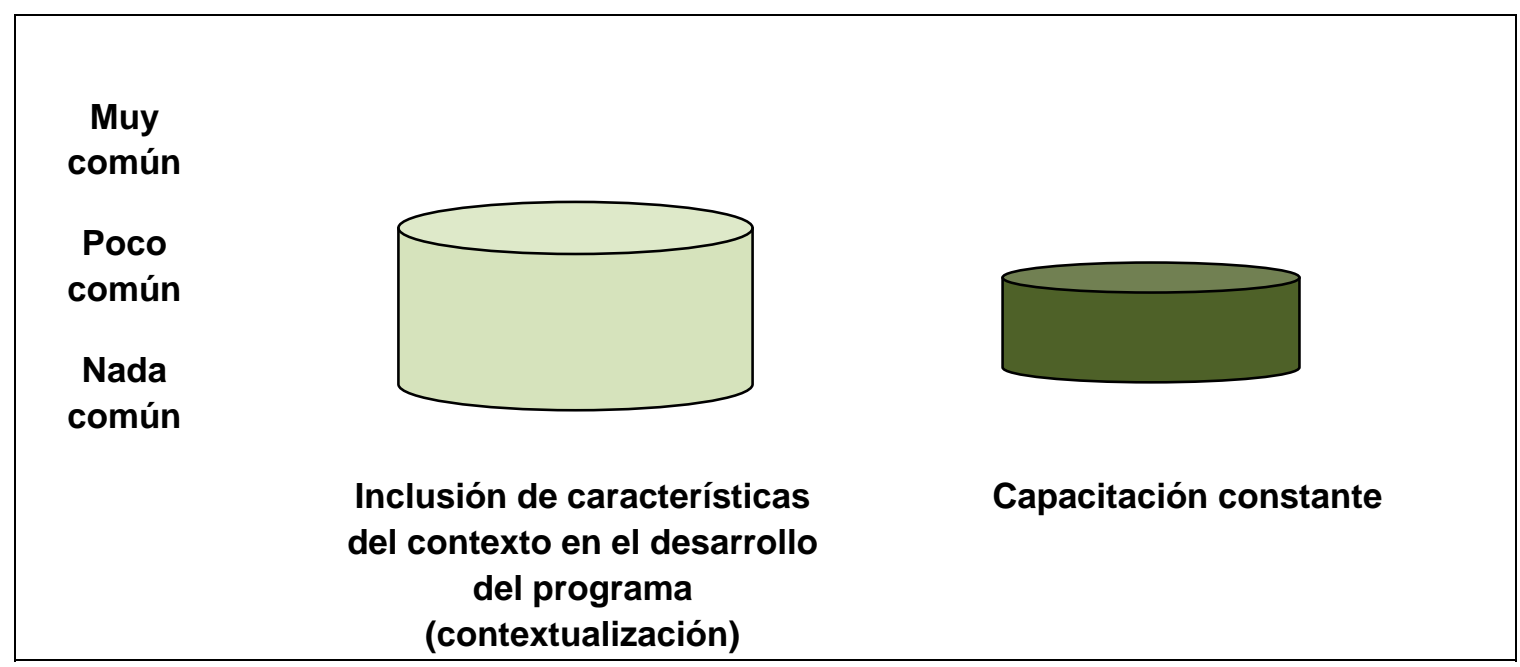

Fuente: Elaboración propia, 2011.

Los programas educativos están en función de la población a quien van dirigidos, por esa razón se deben indagar o diagnosticar las características sociales, culturales, económicas, etarias, entre otros, que caracterizan la población por atender, y de ese modo definir los aspectos ligados a la socialización de los contenidos.

La administración de la educación, desde la perspectiva científica asume la tarea de crear un carácter interdisciplinario entre la educación y el resto de la sociedad, ya que, es necesario complementar todos los conocimientos para que formen una estructura equilibrada y funcional, en ese sentido Méndez (2002, p. 18) asegura que: "ser pertinente es estar en contacto con: -las políticas, el mundo de trabajo, -con la cultura y las culturas, -siempre y en todas partes, con los docentes y los estudiantes" 


\section{Gestión: Sìcación

[Número publicado el 30 de J unio del 2012]

\section{URL:http:// revista digital.eae.fc s.ucr.ac.cr/}

La pertinencia puede definirse como el proceso de interconectar los diversos componentes que estructuran el contexto inmediato, con los principios que mueven a la sociedad, ya que el discente eventualmente se integrará a la sociedad productiva y en ella deberá ajustarse a los lineamientos que imperan, de lo contrario podría ser aislado y convertirse en un anti-social, algo así como una estructura que funciona en los lindes de la sociedad, afectando el equilibrio. En ese sentido es indispensable realizar las conexiones sugeridas por Méndez (2002), de modo que la persona en formación adquiera los conocimientos necesarios para integrarse al círculo social, desde su proceso inicial de educación.

Debe existir un equilibrio, entre las características del programa y la sociedad en general, sin embargo para lograr eso también es necesario utilizar las características naturales del contexto, ubicando al individuo en un proceso educativo que afecte sus propios intereses, ni mucho menos su estructura mental, por lo tanto, la pertinencia se define como un proceso donde el administrador de la educación, articula el programa educativo bajo su supervisión con los elementos contextuales inmediatos para no afectar los intereses de la población, y con las políticas sociales en boga, con el fin de que el programa cumpla una serie de objetivos, no solo educativos, sino de desarrollo personal y social.

El siguiente esquema recoge los datos más relevantes, de los instrumentos aplicados en esta categoría. 
Figura 5

\section{Planeamientos ajustados las metas y objetivos}

a. Los docentes refieren desconocer la meta de la educación.

b. refieren que los planes no pueden adecuarse a un objetivo desconocido.

c. Refieren que el plan se ajusta de acuerdo con la experiencia.

d. Los docentes desconocen el perfil del estudiante, y no pueden dirigir el proceso hacia un tipo de persona modelo a formar.
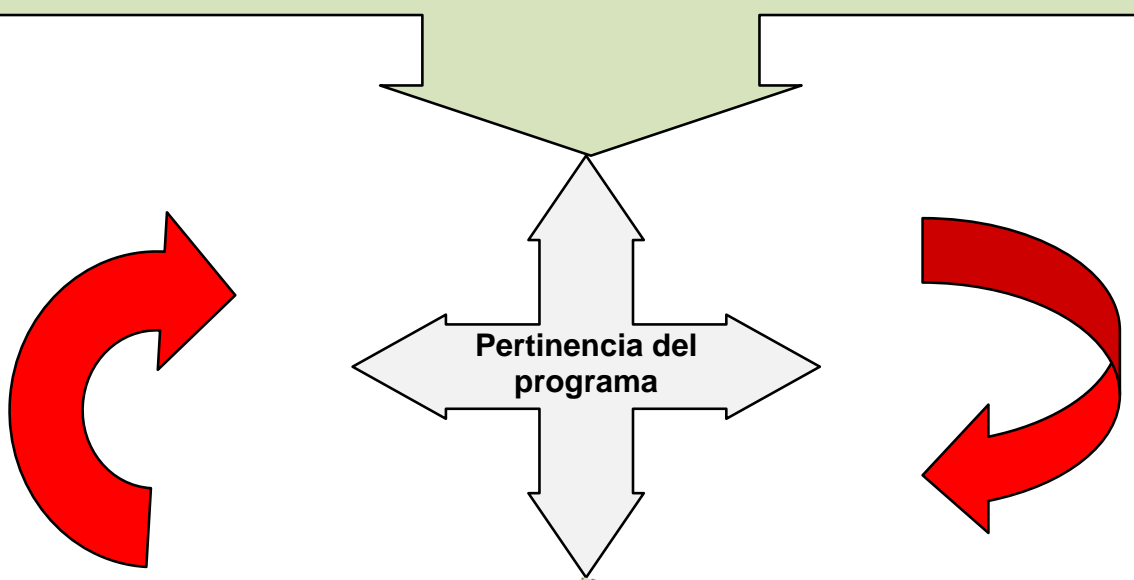

\section{Los objetivos y metas están en contacto con las políticas sociales}

a. El director y los coordinadores refieren como objetivo único, el derecho a la educación y la posibilidad de obtener un título de III ciclo o bachillerato.

b. Los docentes refieren que educan según los contenidos curriculares propuestos por la estructura macro del MEP

c. El director y los coordinadores aducen que solo se visualizan pequeños cambios en el individuo, no necesariamente está listo para insertarse en la sociedad.

d. Los estudiantes refieren que ese proceso no será útil en la calle, ya que no cambia el hecho de que nadie les contrata. 


\section{Los docentes ajustan su plan de trabajo, de acuerdo con: metas, objetivos, relación de metas y objetivos con las características del contexto.}

El programa educativo generalmente es planteado por una estructura de educación que lo ofrece como alternativa a una población, desde esa perspectiva existen programas formales e informales para las poblaciones de las distintas edades. Estos programas son escogidos y desarrollados en diversos estratos, con el fin de cubrir la mayor cantidad de población y cumplir con una garantía social, estipulada en la constitución.

Cada contexto donde se desarrolla cada uno de los programas, posee características que lo identifican y a su vez lo diferencian de otros contextos, eso quiere decir, que cada espacio posee característica etarias, sociales y culturales que definen la población y el tipo de relación social entre los individuos. Por lo tanto, cada programa que se estipule como idóneo debería adecuarse a estas características. En ese sentido, Kaufman (1978), afirma:

La identificación de necesidades es un análisis de discrepancias determinado por las posiciones extremas de:

¿Dónde estamos actualmente?

¿Dónde deberíamos estar?

Y, por tanto específica la discrepancia mesurable entre esos dos polos. Para el éxito del diseño educativo tiene especial importancia que los datos para establecer esos polos sean lo más valederos y representativos posibles. (p. 42)

Un plan de trabajo educativo, es un plan de atención a individuos, y debe ser integral, debe proyectarse hacia la identificación de carencias contextuales y características esenciales, con eso se explica que el plan debe adecuarse a los objetivos contextuales, para cumplir una función real, donde los usuarios se sientan cómodos. En ese sentido, refiere Herrera (2009):

La educación es un proceso, en tanto considera al individuo como sujeto de transformación cualitativa, provocando en él un tránsito de un punto a otro dentro de su maduración o desarrollo La educación es a la vez, un proceso individual o social. Esto 
quiere decir que como proceso se orienta a logro de transformaciones individuales y sociales (p. 41)

En ese sentido podría suponerse que si la educación trabaja en función de la transformación individual, para lograr el cambio necesita reconocer características de cada individuo, y al maximizar ese conocimiento, se logra el conocimiento de toda una comunidad, trazando desde esa arista los objetivos y metas que deben orientar al programa educativo. La administración de la educación como ciencia debe asumir estas posturas para desarrollar exitosamente el programa educativo elegido.

Los instrumentos aplicados permitieron evidenciar un desarrollo del programa educativo sin rumbo fijo, en el sentido de que el programa CINDEA, que se implementa en cárceles, esta únicamente fijado por los lineamientos y contenidos que el MEP propone. El MEP, es una institución macro y no puede verificar la adecuación de un programa en cada contexto donde se desarrolla, en ese punto entra en juego el papel preponderante del administrador de la educación quien debe verificar el objetivo propuesto para la educación en cárceles e incluirlo en la propuesta educativa. No obstante en este caso, se descubrió que ni siquiera el personal del Ministerio de Justicia, conoce el objetivo trazado para la educación en procesos de prisionalización y lo asumen simplemente como la adjudicación de un derecho.

La información recopilada cuando se contrasta con los estipulados teóricos que definen la práctica pedagógica como un proceso orientado a transformar a los individuos y con ellos a la sociedad, tal y como lo define Herrera (2009, p. 41) "Esto quiere decir que como proceso se orienta al logro de transformaciones individuales y sociales", resulta contradictorio, ya que si el análisis indica el absoluto desconocimiento de los objetivos y metas de educar a un privado de libertad, en consecuencia no se podría incluir ese rubro en la planificación de actividades pedagógicas, ni mucho menos suponer que ese aspecto media el plan de trabajo docente, algo así como dejar el programa y el trabajo de los profesionales de la educación a expensas de su propia evolución.

Según lo evidenciado en el análisis, no existe información que concuerde abiertamente con este indicador. 
Las metas y objetivos están en contacto con las políticas sociales.

Este indicador no posee información que permita el análisis, ya que se verificó que la población encargada de desarrollar este programa en centros penales desconoce el objetivo y la metas primordiales, para ejecutar este programa educativo en centros penales, si no existen objetivos y metas fijas, no podría existir tampoco un proceso de conexión pertinente con las políticas sociales actuales de desarrollo y relación.

\section{Análisis global de la categoría "Pertinencia del programa educativo".}

El análisis de los indicadores permitió observar un distanciamiento entre los postulados teóricos sobre la pertinencia de programas educativos, ya que lo referido por Kaufman (1978) sobre la necesidad de proyectar el trabajo que se desarrolla, con base en el conocimiento del contexto, provoca un deterioro de la tarea que defiende Herrera (2009), donde plantea que el proceso sirva para transformar individuos y con ellos grupos sociales, ya que todo el componente desarrollador desconoce los objetivos de la tarea que realiza en el contexto penal, asimismo, no podrían proyectar la meta que deben cumplir, en lo que parece una elección antojadiza y sin fundamentos, de un programa educativo en centros penales.

Los resultados del análisis de esta categoría se evidencian en forma más clara al observar la siguiente imagen. 
Figura 6

Tipo de relación entre los indicadores y la realidad

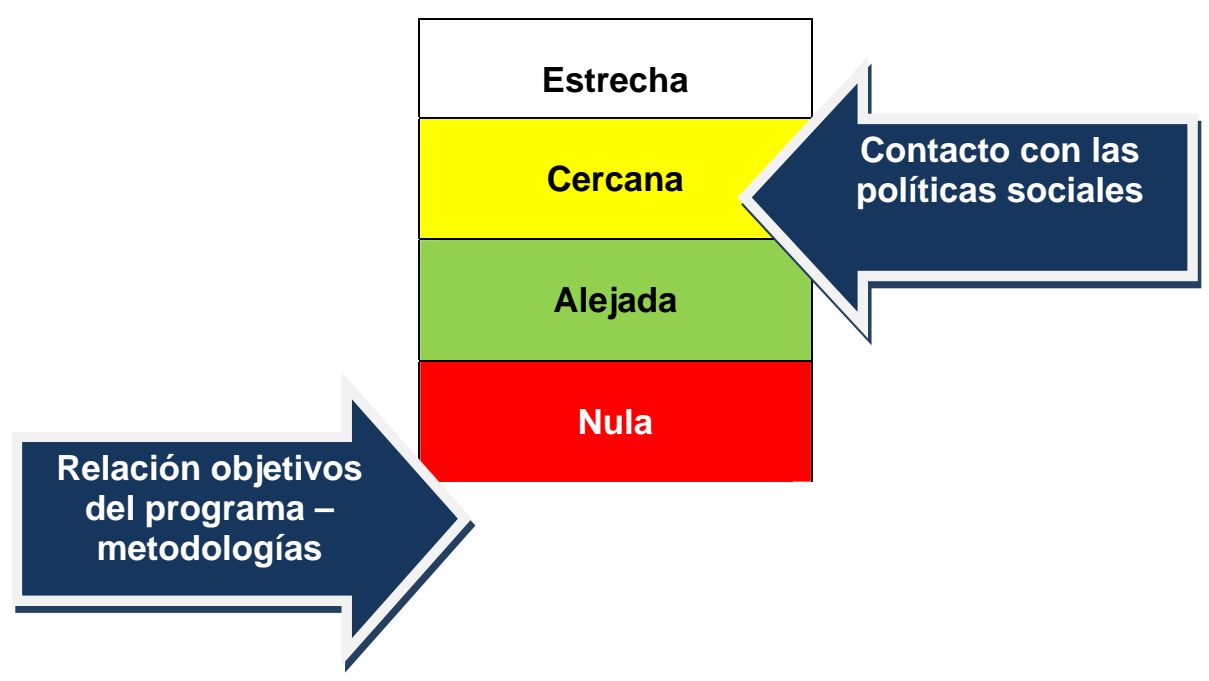

Fuente: Elaboración propia, 2011.

\section{Procesos de evaluación de programas curriculares.}

La administración de la educación como ciencia está en la obligación de medir la efectividad de los procesos que ejecuta, con el objetivo de reestructurar las funciones que fallan y corregir procesos. Además, en su accionar debe contrastar los resultados de esos procesos para mejorarlos o en su defecto terminarlos.

Por lo tanto, una tarea esencial de la administración de la educación, consiste en comparar, y calificar los procesos, con el objetivo de optimizar y actualizar constantemente el programa para asegurar su funcionamiento exitoso, a este caso refiere Lafourcade (2009):

(...) la evaluación constituye una actividad vital para auscultar si la educación genera realmente un alto valor agregado en la formación de los educandos, idóneo para promover a niveles destacables, el desarrollo integral de un país. (p. 123)

La evaluación se consolida como un proceso beneficioso de ajuste, con el que se logran transformaciones en los procesos continuos, pertinentes y adaptados a las necesidades 


\section{Q:isestión:

[Número publicado el 30 de J unio del 2012]
Revista Cientifica Digital ISSN:2215-2288

URL:http:// revista dig ital.ea e.fc s.ucr.ac.cr/

contextuales y a las políticas de la sociedad para la que se forma. La evaluación se presenta como un método para descubrir y atender los puntos débiles, y fortalecer la infraestructura, generando calidad. . A ese parecer refiere Santa María (2000, p. 156) "la calidad es consustancial al trabajo y que forma parte de los valores humanos de lo contrario habrá que revisar que factores están interviniendo para que el trabajo y la calidad no vayan asociados".

El proceso de evaluación se establece como un medio para establecer condiciones constantes de mejora en busca de implementar la calidad, en el sentido de que todos los componentes interactúen en forma precisa.

El diseño de evaluación debe contemplar una fase donde se recolecta información, en una base de conocimientos que funcione como modelo a seguir ante situaciones que pudiesen afectar el proceso y puedan resolverse. Este respecto refiere Kaufman (1978):

La evaluación de una necesidad proporciona datos para identificar y subsecuentemente eliminar necesidades primordiales de nuestro campo de interés. Las carencias, cuando se documentan, proporcionan información básica para el establecimiento de metas valederas, con el fin de asegurarnos todavía más de que nuestro producto educativo es pertinente. (p. 65)

En general, el proceso de evaluación debe estructurase como una práctica organizacional con expectativas de mejora y contrastación de datos creados durante el proceso educativo, que permitan analizar y calificar el desempeño, de modo que se ejecuten las modificaciones que permitan brindarle al programa educativo las características más adecuadas para ajustarse al contexto.

El siguiente esquema recoge los datos recopilados más importantes de esta categoría de análisis. 
Figura 7

Revisión de resultados obtenidos semestralmente

a. Director refiere proceso de reingeniería educativa.

b. Coordinadores no refieren información pertinente
Revisión constante del cumplimiento del objetivo propuesto para la educación en centros penales

a. Indicador no aplica, ya que desconocen el objetivo propuesto
Chequeo de la deserción e investigación para definir causas

a. Director refiere estadística mensual.

b. Coordinadores refieren que la población fluctúa

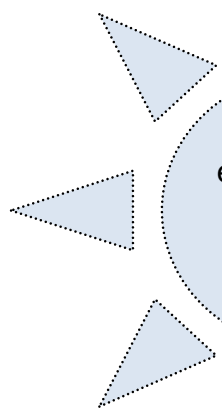

Procesos de evaluación de programas educativos
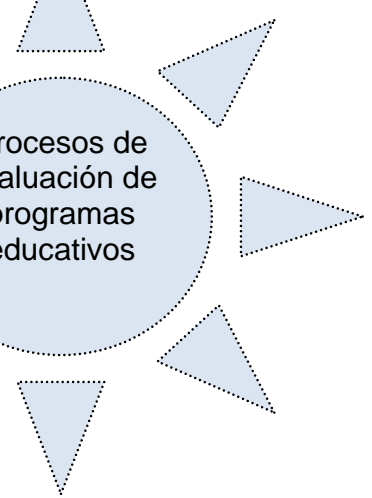

Inclusión docente de temas que demostraron debilidad para fortalecerlos a. Docentes refieren planes remediales, en ciertos contenidos.

Fuente: Elaboración propia, 2011.

\section{Revisión de resultados obtenidos semestralmente.}

Los datos recopilados no registran información relevante con respecto a este indicador ya que el director refirió una revisión a finales del año 2010, con el objetivo de calcular las lecciones que solicitarían para el año 2001, esto no concuerda con los postulados teóricos que pretenden realizar chequeos periódicos de los procesos con el objetivo de mejorarlos, en ese sentido, Kaufman (1978) refiere que cuando se evalúa una necesidad, se proporcionan datos para identificar y eliminar necesidades fundamentales, en este caso el procedimiento descrito 
no aplica con la teoría estipulada y por tanto, parece no cumplir en ningún punto con este indicador.

\section{Chequeo de la deserción e investigación para definir causas.}

Los resultados arrojaron la existencia de una estadística mensual que indica los cambios poblacionales más importantes, en todas las áreas: deserción, traslado, entre otros, no obstante el dato no tiene por objetivo analizar situaciones de disminución de población, sino como una base para la administración de las lecciones.

Nuevamente se presenta una contradicción con los postulados teóricos que afirman que el proceso de evaluación debe ir orientado a mejorar situaciones que dificultan el desarrollo del programa, tal y como refiere Lafourcade (2009):

..la evaluación constituye una actividad vital para auscultar si la educación genera realmente un alto valor agregado en la formación de los educandos, idóneo para promover a niveles destacables, el desarrollo integral de un país. (p. 123)

En este caso el chequeo de aumento o disminución de población se realiza con el objetivo único de aumentar o disminuir lecciones y no como proceso de mejora ni mucho menos para promover el desarrollo integral. Los datos no coinciden con el indicador señalado.

\section{Revisión constante del cumplimiento del objetivo propuesto para la educación.}

Los datos recopilados no pueden ser analizados en esta categoría, pues desconocen el objetivo mencionado.

Inclusión docente de temas que demostraron debilidad para fortalecerlos.

El análisis de los datos permitió observar la existencia de planes remediales, como atención a ciertas carencias del discente, sin embargo, estos planes responden más a las 
necesidades de poblaciones rezagadas que a soluciones de aprendizaje o metodología. Se dispone de este tipo de plan para atender poblaciones discentes rezagados, no obstante no son documentadas para su eventual aplicación en situaciones similares, aspecto que refiere Kaufman (1978, p. 65), “Las carencias, cuando se documentan, proporcionan información básica para el establecimiento de metas valederas, con el fin de asegurarnos todavía más de que nuestro producto educativo es pertinente". En ese sentido se realiza este proceso para atender una situación oportuna de población, no así como situaciones de orden de mejoría del proceso.

\section{Análisis global de la categoría.}

La administración de la educación es una ciencia que necesita realizar procesos de evaluación que le permita reconocer fallas en el proceso y realizar correcciones sobre ese punto, generando soluciones alternativas y apegadas a la evolución del programa. El caso que interesa a esta investigación, evidencia un desapego casi total con los proceso9s de mejora a través de la evaluación, por lo tanto no, se puede intervenir el programa en esta categoría, ya que no existen elementos analizables correspondientes con los indicadores.

La siguiente figura evidencia el grado de realización de procesos de evaluación en el programa educativo que se implementa en centros penales. 


\section{Gestión \\ UE Escuela de Administración Educativa}

[Número publicado el 30 de Junio del 2012]

Figura 8

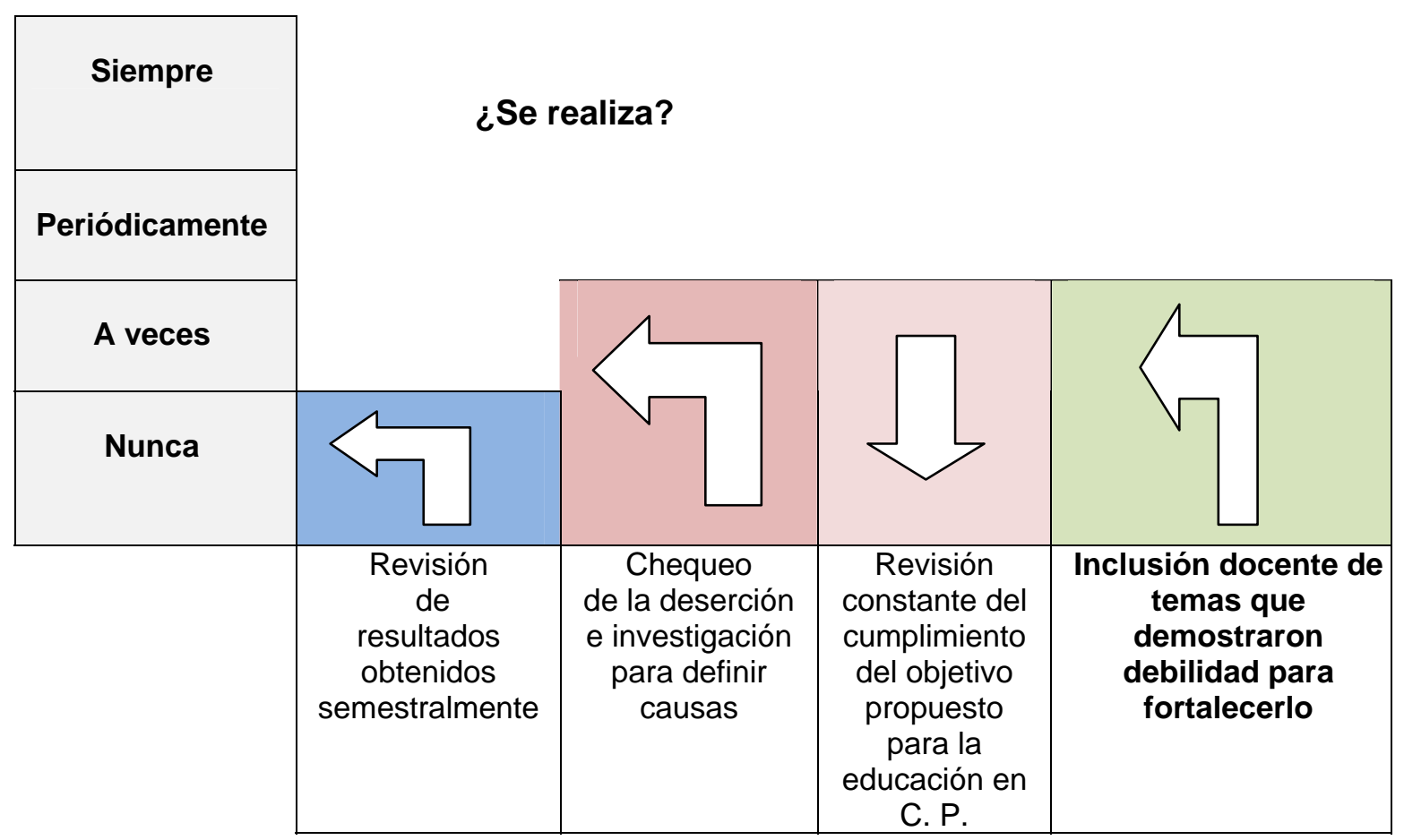

\section{Conclusiones}

La administración de la educación se interesa en el análisis y gestión de programas educativos, porque desde su perspectiva social, intenta promover el desarrollo de modelos educativos eficientes, con el objetivo de favorecer el desarrollo social, e integral de un país, desde la formación de los individuos.

En ese sentido, el administrador de la educación debe indagar la naturaleza del programa educativo que lidera, y para hacerlo debe revisar los componentes que lo estructuran, con el fin de realizar correcciones y ajustarlo a las condiciones necesarias para que su función sea válida e importante. 
El análisis de los datos en lo referente a adecuaciones curriculares, permitió verificar que el programa educativo CINDEA, no ha sufrido procesos serios de adecuación, ni previo, ni posterior a su implementación en centros penales.

La información recopilada durante el proceso de investigación encontró serias deficiencias, con respecto del proceso de adecuación del programa educativo, pues los procedimientos realizados por el personal docente y administrativo no se apegan al sustento teórico estipulado, los cuales se enfocan en el trabajo docente para lograr cambios a través de las contextualizaciones y técnicas de enseñanza, además de las modificaciones que realicen los administrativos en los aspectos de infraestructura y en capacitaciones constantes.

La administración de la educación en su enfoque analítico, permitió verificar que el programa educativo en estudio, no sufrió adecuaciones, para implementarlo en centros penales, mientras que las adaptaciones realizadas responden a circunstancias distintas, no así a mejorar el desarrollo efectivo del programa, ni a optimizar las condiciones del discente.

Los componentes pedagógicos pueden definirse como herramientas que le permiten al docente incrementar el nivel de apego con el proceso, y la interiorización de conocimientos que no rompan con la cotidianidad del discente.

Los datos recopilados permitieron evidenciar que los procesos educativos desarrollados en el programa CINDEA en centros penales, no realiza procedimientos que fomenten la utilización de componentes pedagógicos que incentiven el aprendizaje y la identificación con el proceso de aprendizaje. Dicha carencia se establece cuando no se reconocen objetivos claros ni se realizan capacitaciones, por lo que el personal inmiscuido no realiza adecuaciones ya que no reconoce compromiso en ningún estrato.

El programa CINDEA no recurre a los componentes pedagógicos más adecuados para transformar el proceso en una oferta atractiva para el privado de libertad y esto provoca el aumento de la deserción. Solamente un caso docente incluye elementos en su clase como el lenguaje utilizado dentro del penal y el manejo de la tensión, sin embargo, lo hace en respuesta a su experiencia y no como resultado de capacitación consciente.

El desarrollo del programa carece de componentes adecuados a los discentes privados de libertad, ya que no son elegidos tras un diagnóstico desde la administración de la educación del contexto inmediato, sino que los componentes identificados responden a las necesidades de 
un conjunto o población, sino a situaciones meramente individuales, tomadas por los docentes en forma individual.

Desde la administración de la educación se verifica un carente seguimiento a los procesos de adecuación, los cuales como ciencia, reviste de importancia, ya que sin ellos no se puede asegurar un resultado óptimo y esta característica afecta a toda una población que se somete al proceso.

La pertinencia de un programa educativo está definida como la relación sincronizada entre diversos componentes sociales, por lo tanto, un programa educativo resulta pertinente cuando estipula relaciones significativas y actualizadas con las políticas sociales y con su propia estructura contextual, cuyo objetivo es brindarle herramientas al discente para que se incorpore a la sociedad efectivamente.

En este rubro de la administración de la educación se evidencia débiles nexos con las políticas sociales, ya que también se evidencian distanciamientos con las políticas internas, aspecto que imposibilita cualquier tipo de relación con las políticas sociales, ya que se vislumbra una desestructuración interna.

Los datos recogidos evidenciaron una debilidad importante en lo referente a las relaciones con el contexto de implementación y con las políticas sociales, por lo tanto, el programa educativo implementado en centros penales, no resulta pertinente, ya que, no experimenta procesos de contextualización, ni se fija relaciones con las políticas sociales.

El programa carece de procesos de evaluación, los datos recopilados permitieron verificar la ausencia de procesos de evaluación que permitan la optimización de los procesos educativos, ya que solamente se observan procesos de supervisión sobre la práctica docente misma y sobre los documentos pertinentes a esta práctica, por ejemplo, una de las afirmaciones del director de CINDEA refiere "se solicitan planes anuales, minutas, y listas de asistencia" esto al describir un proceso de supuesta evaluación del programa, por otra parte las coordinadoras realizan procesos semejantes al descrito, una de ellas refiere" se realiza una observación discreta para no entorpecer el proceso de lo contrario se tornaría en un gran distractor" ninguno de los consultados se refiere a la proyección misma que debe tener este programa en cuanto formación académica, ni mucho menos a los objetivos, los cuales en realidad desconocen. 
Desde la administración de la educación se perfila esta carencia como un error fundamental, ya que la evaluación está situada como un referente esencial para actualizar y mejorar una oferta educativa, de lo contrario se convierte en un proceso estático, sin evolución y este adjetivo no calza con la sociedad en la que se desenvuelve.

En general, el programa educativo implementado en centros penales no experimentó procesos de adecuación curricular en ningún momento, tanto de su implementación como de su desarrollo, lo que incumple toda lógica desde la administración de la educación, pues no es posible esperar resultados positivos si no se adecua a la población beneficiaria, esto provoca el aumento de la deserción y el desinterés, además es importante agregar que un proceso sucede al siguiente, la falta de adecuación le resta pertinencia al programa lo que lo convierte en un proceso sin sentido, y desde la administración de la educación, este tipo de caracterización debería provocar la modificación de la estructura con el fin de enlazar este proceso con las políticas sociales.

La administración de la educación fomenta la evaluación constructiva constante, y este programa carece de ella, para esta ciencia es muy importante realizar este proceso, ya que de él dependen las innovaciones y los cambios positivos para con la población beneficiaria, de lo contrario, la educación no representa nada. En un listado básico de carencias que surgen con la falta de diagnóstico y evaluación está la de los componentes educativos, que sirven para facultar al proceso de cualidades atractivas para el discente quien se integra y se mantiene como resultado de este aspecto atractivo.

La administración de la educación como ciencia descubre que este programa puede ser mejorado, siempre y cuando se utilicen las bases aptas para este desarrollo, y desde la perspectiva científica de esta disciplina, esto solo se logra en un proceso de análisis constante, conocimiento y capacitación para comprometer ven la tarea a todos los implicados.

La administración de la educación posee un papel preponderante en la implementación de educación en centros penales, ya que es desde esta perspectiva que se realiza un proceso eficiente, balanceado, eficaz y pertinente y de esa manera someter a los privados de libertad a reestructuraciones reales que les permitan incorporarse a la sociedad en condiciones positivas y productivas. 


\section{Referencias bibliográficas}

Aguerrondo, M. (2001). La calidad de la educación: ejes para su definición y evaluación. Recuperado en: http://enlaceconsulting.net/articulos/Lacalidaddelaeducacion.pdf

Alva S. M.N. (2003). Las tecnologías de la información y el nuevo paradigma educativo. Recuperado en: edp721.cjb.net

Arias S., O. (2007). "No hay desarrollo sin planificación". La Nación [en línea]. Recuperado de: http://www.nacion. com/ln_ee/2007/enero/25/opinion972615.htm

Botero, C. (2009). "Cinco tendencias de la gestión educativa". Revista Iberoamericana de Educación. Recuperado en http://www.rieoei.org/deloslectores/2811Botero.pdf

Castro, R. (1996). En busca del significado: supuestos, alcances y limitaciones del análisis cualitativo. En Szasz, I. y Lerner, S. (comps.). Para comprender la subjetividad. Investigación cualitativa en salud reproductiva y sexualidad. México: Colegio México.

¡Error! Referencia de hipervínculo no válida.. Periódico El País. Recuperado en: www.elpaís.cr.el

Fallas A., V.H. y Herrera S., V. (2009). Evaluación e implementación de un sistema de calidad en instituciones educativas. San José, Costa Rica: EUNED.

Garbanzo V., G. (2001). "La administración curricular en la educación superior: caso de la Universidad de Costa Rica". Revista Educación, 25(2), setiembre, pp. 25-39. Recuperado en: http://www.redalyc.org/redalyc/html/440/44025203/44025203_1.html

Hernández, A. (2009). Administración o gestión de la educación: un análisis desde los acertijos de la complejidad. Recuperado en: http://www.revista.clap.edu.mx/wpcontent/uploads/2009/06/alex-admon-compl.pdf

Kaufman, R. (1978). Planificación de sistemas educativos. USA: Editorial Trillas.

Lafourcade, P. (2009). Evaluación institucional. San José, Costa Rica: EUNED.

La Gaceta. (2006). Reglamento Ley de igualdad de oportunidades para personas con discapacidad. Ley $7600 . \quad$ Recuperado de: http://www.google.co.cr/url?sa=t\&rct=j\&q=\&esrc=s\&source=web\&cd=5\&ved=0CFYQFjAE \&url=http\%3A\%2F\%2Fdocumentos.cgr.go.cr\%2Fcontent\%2Fdav\%2Fjaguar\%2FUSI\%2Fn ormativa\%2FOtros\%2FOTROS-115664.doc\&ei=IFHtT-

epNY2I8QT3rvyGAg\&usg=AFQjCNGMiPxzaFs2RiVDV96-

9dFG3IZdTg\&sig2=Z_yeXNPP7KIgSXmHdcjRAQ

López, G. (2009). La educación en adultos. Recuperado de: http://www.csisif.es/andalucia/modules/mod_ense/revista/pdf/Numero_23/GEMA_\%20LO PEZ\%20GUERRERO_1.pdf.

Maya, A. (2002). Conceptos básicos para una pedagogía de la ternura. Colombia: Impresora Obando.

Méndez M., J. (2002). La evaluación de programas académicos de Educación Superior a Distancia: La búsqueda de la calidad. En: IX Encuentro Internacional de Educación Superior a Distancia: Aprender juntos a vivir la diversidad, Universidad de Guadalajara, México.

Orozco, J.C. (2008). La pedagogía en los umbrales de la ambigüedad. Recuperado en: www.pedagogica.edu.co/storage/ps/articulos/pedysab04_08arti.pdf

Peralta, M.V. (2008).Una pedagogía de oportunidades. Chile: Ëditorial Andrés Bello. 
[Número publicado el 30 de J unio del 2012]

URL:http:// revista dig ital.eae.fc s.uc r.ac.cr/

Pérez J., R. (2000). La evaluación de programas educativos: conceptos básicos, planteamientos generales y problemática. Revista de Investigación Educativa, 18(2), pp. 261-287. Recuperado de: http://www.doredin.mec.es/documentos/007200230097.pdf

Rueda, L. (1999). "Investigación y evaluación educativa: bases teóricas y conceptuales". Revista Atención Primaria, 23(8). Recuperado de: http://www.ia.ufrrj.br/ppgea/conteudo/conteudo-2007/T11SF/Canrobert/Investiga\%E7\%E3o_e_evolu\%E7\%E3o.pdf.

Santa María, J. (2000). Transformar la educación en un contrato de calidad. Barcelona: Editorial CISSPRAXIS S.A.

Senlle, A. y Gutiérrez, N. (2005). Calidad en los servicios educativos. España: Díaz de Santos. Recuperado de: http://www.arevalodeleon.com/focim/Bodega/PATRICIA\%20AIDA/23julio-literatuta\%20disertacion/calidad\%20en\%20los\%20servicios\%20educativos.PDF

Vargas, A. (2001). La cultura evaluativa en la Universidad de Costa Rica. Su construcción desde la evaluación docente. Tesis para optar por el grado de Doctorado en Educación. Universidad de Costa Rica. San José, Costa Rica.

Wamsley, R. (2003). Foro sobre el delito y la sociedad. Volúmenes 1 y 2, diciembre 2003, pp.67-75. Austria: Art de Editorial de las Naciones Unidas. 